University of Rhode Island

DigitalCommons@URI

Open Access Master's Theses

2007

\title{
Multi-Dimensional Relating: A Re-Conceptualization of Emotional Dependency in Female Couples
}

A. Cassandra Golding

University of Rhode Island

Follow this and additional works at: https://digitalcommons.uri.edu/theses

\section{Recommended Citation}

Golding, A. Cassandra, "Multi-Dimensional Relating: A Re-Conceptualization of Emotional Dependency in Female Couples" (2007). Open Access Master's Theses. Paper 1630.

https://digitalcommons.uri.edu/theses/1630

This Thesis is brought to you for free and open access by DigitalCommons@URI. It has been accepted for inclusion in Open Access Master's Theses by an authorized administrator of DigitalCommons@URI. For more information, please contact digitalcommons-group@uri.edu. 
MULTI-DIMENSIONAL RELATING:

A RE-CONCEPTUALIZATION OF EMOTIONAL DEPENDENCY IN FEMALE COUPLES

BY

A. CASSANDRA GOLDING

A MASTER'S THESIS SUBMITTED IN PARTIAL FULFILLMENT

OF THE REQUIREMENTS FOR THE DEGREE OF

DOCTOR OF PHILOSOPHY IN

PSYCHOLOGY

UNIVERSITY OF RHODE ISLAND

2007 


\begin{abstract}
The purpose of this study was to reconceptualize emotional closeness in women's relationships through the introduction of a model of healthy emotional reliance (HER). This study intended to develop and validate a psychometrically sound measure of female healthy emotional reliance that will provide a means by which to measure a re-conceptualization of the healthy portions of merger in female couples. The original focus of merger, based on psychoanalytic theory, has been pathological. More recently it has been to some extent re-conceptualized as a healthy and functional emotional closeness. The combination of functional and dysfunctional components of merger has led to confusion in the literature. It is, therefore, the aim of this investigation to re-conceptualize the functional components of merger as healthy emotional reliance while reserving the dysfunctional components for the original term, merger. This approach was grounded in social constructivist theory and feminist ego psychology, which emphasizes the role of gender-socialization on women's and men's self-concepts, behavior and personality traits. This investigation includes development of a scale to measure healthy emotional reliance and determined some predictors of subscales. A nationwide and geographically diverse female sample of 368 participants with an age range of 18 to 81 years completed an online survey including the newly constructed measure of healthy emotional reliance. Participants were recruited through a chain (snowball) method.

Principal Components analysis was used to determine whether four hypothesized hierarchical components (Interdependence, Emotional Autonomy, Differentiation and Satisfaction) originally thought to underlie a single construct of
\end{abstract}


healthy emotional reliance, would characterize the data. However, what emerged was a multidimensional model comprised of three separate components (two of which were re-conceptualized upon further consideration of their content): Interdependence, Attachment and Negative Dependence and therefore, no total scale score representing the single construct of healthy emotional reliance emerged. Internal consistency estimates using Cronbach's alpha suggested high reliabilities for each of the three subscales.

Validity hypotheses testing using bivariate correlations, showed a significant positive correlation between Interdependency and the Healthy Dependency sub-scale of the Relationship Profile Test indicating high levels of interdependency associated with high levels of healthy dependency. Due to the change in conceptualization of Component 2, Attachment (originally Lack of Emotional Autonomy) and Component 3, Negative Dependence (originally Lack of Differentiation), it is difficult to assert construct validity claims. However, Negative Dependence and the Destructive Overdependence subscale of the Relationship Profile Test showed a significant moderate positive correlation indicating that the Negative Dependence subscale is measuring something like destructive overdependence which is defined by Bornstein and Languirand (2003) as maladaptive and inflexible dependency.

The three subscales correlated with each other in interesting ways. Interdependency was moderately positively related to Attachment suggesting that as attachment increases so does interdependency. A modest negative correlation between Attachment and Negative Dependence indicates that Attachment is inversely related to negative dependence such that an unhealthy or over-dependency does not facilitate 
attachment. Thus, Attachment is somewhat related to the lack of unhealthy dependency. The results of this study suggest that autonomy and attachment are not polar opposites on the same dimension, but rather encapsulate two separate dimensions towards which one can be strongly orientated simultaneously. 


\section{Acknowledgements}

This Master's Thesis could not have been completed without the support and dedication of my major professor, Trish Morokoff and committee members, Kat Quina, Joe Rossi, and Pat Burbank. I want to give a special thank you to my friend and confidant, Christine Sieberg for her endless support through this process and my mother, Anita Golding for her undying faith in me and unconditional love that lies behind all my accomplishments. I am indebted to the over 400 women from the queer community who made this research a reality and whose voices I hope to continue to capture in future research efforts in an attempt to strengthen social change for the equality of all persons.

I am also grateful for the financial support provided by the University of Rhode Island Graduate School which has afforded me the time and energy to pursue this research. As is explained in the following text, this very work exemplifies the ways in which we need each other and the benefits of being willing to rely on and support one another throughout our individual journeys. 
Abstract

Acknowledgements $\quad \mathrm{v}$

Table of Contents vi

List of Tables viii

List of Figures $\quad$ ix

I. Introduction
A. Statement of the Problem
B. Purpose of the Study
C. Significance of the Study
D. Reason for Selection of Problem

II. Literature Review

A. Theoretical Approaches to Merger: 11

1. Object-Relations/ Psychodynamic Approach 12

a. Merger as Pathology 14

2. Systems Approach 17

3. Ego-Syntonic/ Social Constructivist Approach 19

B. Empirical Findings of Closeness (Merger) in Lesbian Relationships 24

III. Proposed Model: Model of Healthy Emotional Reliance (HER) 35

A. HER Model Variables $\quad 37$

B. Variable Relationships $\quad 40$

C. Hypotheses $\quad 45$

IV. Methods $\quad 46$

A. Participants 46

B. Inclusion/ Exclusion Criteria $\quad 47$

$\begin{array}{ll}\text { C. Procedure } & 48\end{array}$

$\begin{array}{ll}\text { D. Measures } & 50\end{array}$

V. Results
A. Demographics 56
B. Scale Development $\quad 57$
C. Descriptive Statistics $\quad 60$
D. Tests of Hypotheses 62

VI. Discussion $\quad 68$

A. Limitations of the Study and Future Directions 75

$\begin{array}{ll}\text { B. Conclusion } & 79\end{array}$

$\begin{array}{lr}\text { Tables and Figures } & 81\end{array}$

Appendix A: Original HERS Items $\quad 91$

Appendix B: Final HERS Items $\quad 93$ 
Appendix C: Measures

Appendix D: Informed Consent

Bibliography 


\section{List of Tables}

Table 1: Demographic Statistics for Participants

Table 2: Private and Public Sexual Orientation of Participants

Table 3: Ethnicity, Education Level, Geographical Region of Participants

Table 4: Rotated Component Matrix

Table 5: Rotated Component Matrix- Group 1 (18 Items)

Table 6: Rotated Component Matrix- Group 2 (18 Items)

Table 7: Rotated Component Matrix- Full Sample (18 Items)

Table 8: Average Item Means and Standard Deviations for each Subscales of the HERS

Table 9: HERS item means and standard deviations

Table 10: Inter-correlations among Subscales for Full Sample and by Group

Table 11: HERS Subscales Cronbach Alpha for Full Sample and by Group

Table 12: Intercorrelations Between Measures

Table 13: Intercorrelations between Relationship Satisfaction, Subscales and Outness 


\section{List of Figures}

Figure Number

Figure Title

Page Number

Figure 1: Healthy Emotional Reliance (HER) Model 89

Figure 2: Three component scree plot

90 


\section{Statement of the Problem}

\section{Introduction}

The literature presumes that female socialization and development is such that female couples are more connected and affiliated than other couple types (Elise, 1986; Gilligan, 1982; Kirkpatrick, 1991; McKenzie, 1992; Mitchell, 1988; Pearlman, 1989). As Hancock (1995) notes, women are socialized to "place relationship before autonomy" (p. 410); however, relationship issues between female couples are traditionally analyzed from the masculine gender role conception that healthy relationships are based on separation (Mencher, 1997). As a result, clinical observations of lesbian couples in therapy have been the basis of assertions made by several authors (Burch, 1982; 1985; 1993; 1997; Causby, Lockhart, White, \& Greene, 1995; Krestan \& Bepsko, 1980; Pearlman, 1989; Peplau, Cochran, Rook, \& Padesky, 1978) that lesbian couples, more than any other couple type, present with a problem referred to as merger (also referred to as fusion or enmeshment).

Different theoretical branches of psychology have suggested multiple reasons to account for merger in female couples. For example, traditional psychodynamic and object-relations theories conceptualize merger as an unhealthy relationship strategy indicative of psychological regression. Merger is defined as a loss of individual identity in the service of the identity of the couple. These approaches posit that merger is more prevalent in female couples due to the sharing between two women of similar infantile developmental processes of attachment and separation from the mother (Chodorow, 1978). This perspective has cast female couples in a pathological light which contributes to an already largely rigid and sexist social-political climate and, consequently, adversely affects female couples as they seek support and acceptance in 
communities the world over. The systems perspective suggests that merger is a ramification of a hostile socio-political environment. Proponents of this theory, purport that merger may be a coping mechanism enacted by female couples to battle the homophobic and unsupportive pressures they come up against daily. Mencher's egosyntonic perspective proposes that positive parts of merger are attuned with the ways in which women are socialized and can be indicative of a healthy relational style that is more conducive to the ways in which women navigate interpersonal affairs.

Relationships of all types must struggle with the push and pull of closeness or intimacy and distance or independence, and struggle to balance the two. This is a fundamental, lifelong task that all couples, regardless of sexual orientation, must endure (Blumstein \& Schwartz, 1983; Burch, 1982; Causby, et al., 1995; Pearlman, 1989; Peplau, et al., 1978). The notions of separation and interrelatedness, often referred to as psychological boundaries, are central in negotiating any romantic relationship (Carroll, Hoenigmann-Stovall, Turner, \&Gilroy, 1999). While conflicts surrounding issues of differentiation and autonomy are recognized in all types of relationships (Burch, 1982) and merger, to some degree, is an expected beginning to most romantic relationships (Pearlman, 1989), lesbian couples, in particular, have been depicted in the clinical literature as having a merged, enmeshed or fused relational style (Biaggio, Coan, \& Adams, 2002; Burch, 1982; Carroll, et al., 1999; Elise, 1986; Krestan \& Bepsko, 1980; McKenzie, 1992; Mitchell, 1988; Pardie \& Herb, 1997; Pearlman, 1989; 1995).

Despite an abundance of theorization about female couples and relationship closeness, to date there exists no psychometrically rigorous scale to measure relationship closeness in non-pathological terms among female couples. Although, 
Colwell (1988) developed the Merger/Disengagement Scale (MDS) in an attempt to measure gender differences in styles of emotional closeness, her findings were contradictory to expected relationships as well as the clinical literature which together has hampered psychometric rigor. Among a sample of 26 lesbian, gay male and heterosexual couples, gay males were found to merge more than lesbians; however, lesbians were found to be the least disengaged. Items reflected the traditional conceptualization of merging as needy dependency and a lack of ego development taken from "the descriptions various theorists have given emotional states of being fused, close, distant and disengaged" (Colwell, 1988, p. 60). Therefore, these items inherently epitomize pathological views of merger and not healthy or adaptive functions of closeness. Further, despite predicted gender differences, separate validity for men and women was not established. The lack of significant results precludes content validity and suggests the need for further validation studies.

Colwell conceptualized merger and disengagement on a continuum. Her results lead her to conclude that the term merger should be dropped from the clinical literature in favor of the phrase "avoidance of conflict in the service of maintaining intimacy" (p. iv). Taken together, these findings suggest that more research is needed to adequately define closeness in female relationships and measure it in a reliable and valid way. Thus, a measure of non-pathological closeness, able to measure relationship closeness in female couples, will greatly add empirical data to overwhelming theorization about the issues surrounding merger and female couples.

The dearth of empirical findings on merger in female couples highlight the complexity of closeness in female relationships. Lesbians seem to report both high 
levels of closeness and high levels of satisfaction in their relationships, yet it is still unclear when and if personal boundaries are lost in lesbian partners. Peplau et al. (1978) found that personal autonomy and dyadic attachment are two distinct dimensions in lesbian relationships capable of simultaneous relationship roles, and that dependence and independence issues were among the most recognized causes of break-ups in lesbian relationships. Thus, dependency concerns seem to play a significant role in female couples. It would thus be of interest to determine how closeness and intimacy relate to dependency. Further, the literature has not investigated the role that outness, the extent to which a man or woman discloses her minority sexual orientation, plays in managing closeness and dependency between women in relation.

\section{Purpose of the Study}

This study utilized a process perspective, in which closeness in female relationships is seen as the result of several interacting factors over time, on several levels: within the individual, between partners, and amidst the couple-environmental interface. Feminist ego psychology, which emphasizes the role of gender-socialization on women's and men's self-concepts, behavior and personality traits, also significantly contributed to the social constructivist theory underlying this investigation. As part of this study, a construct of healthy emotional reliance for female couples within the context of female gender role socialization was conceived. This study aimed to answer the following four questions:

(1) Is healthy emotional reliance a unidimensional construct or the result of several underlying factors?

(2) Is healthy emotional reliance in female couples a different construct from intimacy? 
(3) Does degree of outness affect healthy emotional reliance in female couples?

(4) How does healthy emotional reliance relate to relationship satisfaction in female romantic relationships?

It was this study's aim to re-conceptualize female relational issues using a feminist ego theoretical orientation so as to introduce a model of healthy emotional reliance (HER). Further, this study intended to develop and validate a psychometrically sound measure of female healthy emotional reliance that will provide a means by which to measure a re-conceptualization of merger in female couples. The purpose of this study was to differentiate psychologically functional and dysfunctional components of the merger construct.

The original focus of merger, based on psychoanalytic theory, has been pathological. More recently it has been to some extent re-conceptualized as a healthy and functional emotional closeness. The combination of functional and dysfunctional components of merger has led to confusion in the literature. It is, therefore, the aim of this investigation to re-conceptualize the functional components of merger as healthy emotional reliance while reserving the dysfunctional components for the original term merger. This investigation examined what would constitute healthy emotional reliance and determined some predictors in a female sample.

Significance of the Study

Estimations of the adult gay and lesbian population of the United States range from two to ten percent of the total population. The 2000 United States Census reported 601,209 total unmarried same-sex partner households (104,148 male and 297,061 female couples; 1.2 million individuals) living in 99.3 percent of all counties across the 
United States (Smith \& Gates, 2001). It is important to note that counts of same-sex couples do not include any single gay men or lesbians, as the Census questionnaire did not include questions about sexual orientation, sexual behavior or sexual attraction. Due to re-categorization of marital status and gender by the US Census Bureau, Badgett and Rodgers (2003), among others, posit that the Census Bureau missed at least 16 to 19 percent of all gay or lesbian couples. They reflect that if 5 percent of the U.S. adult population is gay or lesbian and approximately 30 percent of gay men and lesbians are coupled (as several surveys suggest), then Census figures did not count 62 percent of all same-sex couples. Given the above considerations, some estimates report that as many as approximately 25 million U.S. citizens are either gay or lesbian (Sullivan, 1995).

In addition, it is important to consider that the estimation of how many people are gay and lesbian depends on how homosexuality is defined. Many more people report sexual feelings for someone of their same-sex than report recent sexual experiences with someone of the same sex. Also, people identify their sexuality in a variety of ways; many estimations rely on counts of people who have identified themselves as gay or lesbian, however these counts do not include individuals who may be in a same-sex relationships or have sexual feelings for people of the same sex, but do not identify as gay or lesbian. Lastly, due to the stigmatization of homosexuality, samesex attraction is likely to be more under reported than over reported. Therefore, no one really knows the parameters of the gay and lesbian population, coupled or single.

Nevertheless, although the figure from the 2000 Unites States Census of 297,061 female couples is most likely a gross underestimate by somewhere between sixteen and 62 
percent, this statistic alone speaks to a sizable proportion of the population that this study addresses.

This investigation significantly adds to the scant empirical literature about female couples in general as well as women in relationships with other women without specifying a lesbian identity. Few, if any, studies have focused on understanding the function closeness in relationships, particularly romantic relationships between women. Further, even fewer attempts have been made to quantify the phenomena of relational closeness in female couples.

Although, this study cites literature on lesbian relationships, this is a study about how women relate as women, rather than perpetuating a behavioral divide based on sexual identity. In the past, those studies that have explored these concepts (Blumstein \& Schwartz, 1983; Causby, et al, 1995; Mitchell, 1988; Peplau, et al., 1978) have done so by conceptualizing a divide between lesbians and heterosexual women, rather than appreciating the similarity among all women and the relational value of all types of relationships. It is important to conceptualize women in relationships with other women separate from sexual orientation for several reasons. First, a large part of the females coupled with other females population is missed by studies that only recruit lesbian or bisexual women. Many women in relationships with other women do not identify as lesbian or bisexual. Some women may choose to not adhere to any label at all, and still, others may identify as heterosexual despite their current same-sex relationship status.

Second, how we think of sexual orientation determines how we label others and how we label ourselves. For some women, sexual orientation may be interpreted as 
based upon the gender one is attracted to as opposed to the biological sex of one's partners. Thus, if a woman is coupled with an androgynous or male gendered woman, she may consider herself as heterosexual. On a similar note, sexual orientation may mean little to some women, despite societal emphasis; she may rather engage in sexual or romantic behavior based on emotional orientation and choose partners based on their emotional connection appeal. In such a case, this woman may not find lesbian, bisexual, straight, gay or heterosexual a suitable label for herself. Further, the very terms, lesbian, gay, bisexual, and straight can have various meanings for different people. These terms could refer to behavior as opposed to attraction or attraction as opposed to behavior. Therefore, a woman attracted to women, but married to a man may find herself behaviorally heterosexual, but attraction wise, lesbian. Similarly, a woman who is exclusively with women sexually, but is attracted to men as well, may identify as lesbian, bisexual or heterosexual, depending on her interpretation of the terms.

Additionally, as will be further explained in the following literature review, women, regardless of sexual orientation, gender orientation, or other-attraction, regardless of labels given or labels chosen, have been socialized as women. Therefore, the intersection of female socialization and relationship forces are important factors in determining how women relate with other women. As explained by Garnets and Kimmel (1993), it is important to conceptualize woman as women regardless of their sexual orientation identity due to the common socialization patterns experienced by the majority of women in a given culture. Therefore, they conclude that lesbians and heterosexual women have more in common then lesbians and gay males (Garnets \& 
Kimmel, 1993). Gender is the single strongest factor in how we perceive others (Peplau \& Garnets, 2000. Before we ask if a baby is White, Black, Hispanic, Native American, or Asian, small, large, or medium, the baby's name; before we ask if the baby is healthy, we ask is it a "boy or a girl" and treat the little bundle accordingly. In conclusion, women are first socialized as women and then according to any prescribed sexual orientation (Hancock, 1995; Kirkpatrick, 1991; Miller, 1976; Pardie \& Herb, 1997).

However, it is equally important to make explicit that this study does not adopt an essentialist perspective, but rather a social-constructivist perspective. Thus, the gender differences discussed throughout this research are not intended to be evidence of biological or inherent differences between men and women, but rather ramifications of differences in socialization between men and women.

This study aimed to empirically develop a scale to measure healthy emotional closeness, and, thus, re-conceptualize the construct merger, aiding in better understanding and re-interpreting of the findings of previous studies. A scale focused on the healthy aspects of emotional closeness rather than current scale conceptualizations based on the pathological construct of merger will greatly add to the literature. These results will also add to the literature on gender differences and female psychology in exploring women's development and socialization. Lastly, the empirical findings from this study may prove useful to mental health professionals in their pursuit to better understand facets associated with healthy aspects of closeness in female relationships rather than pathological aspects. Pardie and Herb (1997) point out that the shift of a therapist's view concerning the psychological health of a couple will 
unequivocally influence the focus of treatment and possibly enhance the prognosis of the relationship.

\section{Reason for Selection of the Problem}

As the political climate of Western society becomes more accepting of gay male and female couples, the continuing efforts of researchers to understand and further explore lesbian issues from within the context of female gender norms becomes more and more imperative. Because it seems that the concept of closeness is mis-understood in the past clinical literature, lesbian couples seeking therapy or legitimacy in their community may be adversely affected by the mistaken pathologizing of their closeness or even accused of "dependency". As a lesbian and therapist, this investigation is personally valuable to my areas of research and potential clients that I seek to treat.

It is virtually impossible to manipulate what happens in intimate relationships in order to test the underlying dynamics and the function(s) of these dynamics. Further, it is also impossible to assess the existence of a construct that has not been adequately defined. Moreover, assessing an ill-defined construct proves even more credulous when the construct is not yet determined to be distinguishable. Thus, accurately assessing the underlying dynamics of lesbian relationships, specifically, the concepts, functions, manifestations, and ramifications of emotional closeness and differentiation as they manifest in female relationships, necessitates first assessing and defining the construct of closeness itself. Therefore, the development of a rigorous scale that is capable of explicating a distinct definition of closeness and measuring healthy aspects of female relationships is invaluable to a field largely unexplored and not yet scientifically evaluated. 


\section{Literature Review}

The following literature review section provides the theoretical background and foundation for this study. Several theoretical perspectives about gender socialization and family dysfunction are explicated in an attempt to show how our current understanding and study of romantic relationships between women have been shaped. Included is a discussion of several variables related to the current conceptualization of merger and evaluates them according to several psychological and developmental theories. This review will provide a critical lens through which the clinical literature on intimate relationships between women may be re-conceptualized.

This section begins with a discussion about merger as a developmental construct of object relations theory and provides several definitions of the concept of merger. The resulting psychodynamic ideas about adult pathology as the result of merger fantasies and how the negative aspects of merger characteristics have been used to pathologize very close romantic relationships between women are then expounded upon. The literature on the systems approach to merger in female couples as well as the ego-syntonic/ social constructivist approach to merger in female couples is summarized. Following, the empirical research literature about merger in lesbian relationships is put forth. This review evaluates how these theories about merger relate to a general discussion of female sexuality and socialization, gender roles and traditional conceptions of healthy relationships leading to alternative conceptualizations of merger aside from pathology. Specifically a new model for the prevalence of merger in female couples. Descriptions of each of the model's components are then offered. This section concludes with the specific hypotheses to be tested in this study. 


\section{Theoretical Approaches to Merger}

\section{Object-relations/ psychodynamic approach}

Some developmental theorists such as Chodorow (1978) assert that the higher levels of relatedness and empathy experienced by women is a consequence of women having different developmental experiences than that of men. First, mothers are assumed to be the primary parent. For males, separation from the mother, the primary mechanism for developing gender identity, occurs due to the marked difference that is perceived by both the male infant and his mother in order that the male may identify with an available male model. Because women do not separate from their primary parent in order to develop gender identity and instead experience a prolonged sense of oneness encouraged by the sameness between mother and daughter, women have the experience of a very close, intimate relationship with their primary parent. As a result, women are hypothesized to develop gender roles through identification rather than separation, and, as adults, to seek close emotional relationships to replicate the close relationship between mother and daughter. Such relationships are not typically available to women in relationships with men who develop their identity by separating from their primary parent. Chodorow (1978) hypothesizes that women thus often seek their desired emotional fulfillment through relationships with children, because for women in relationships with men, children are the only people available for such intimacy. This, in turn, re-starts the cycle of primary parent intimacy or separation based on the child's biological sex.

However, lesbian relationships provide an alternative means for the emotional fulfillment women seek through relationship. When two women are in a romantic 
relationship with each other, there is theoretical reason to expect that closeness of the emotional relationship may increase dramatically. Thus, lesbian couples have frequently been described in the clinical literature as evidencing a merged, enmeshed or fused relational style (Burch, 1985, 1993; Green, 1990; Causby, et al., 1995; Krestan \& Bepsko, 1980; Pearlman, 1989; Peplau, et al., 1978, Mencher \& Slater, 1991).

According to psychodynamic theory, the mother and daughter connection is complicated and prolonged because of the mother's unconscious identification with her daughter. As a result, the daughter does not form a solid sense of herself apart from her mother. In fact, her self-image is based upon a "self-in-other" relationship and is, therefore, less steadfast and secure. Thus, merger in lesbians is the result of the unconscious simulation to the complex and prolonged connection held by mother and daughter and the lack of separate identification that ensues (Burch, 1982; Carroll et al., 1999).

Chodorow's (1978) theory of female socialization puts forth that women search for an intense emotional connection, a loved object, such as the one experienced in the mother-daughter dyad. Thus, in a lesbian relationship, it is reasonable to expect that each woman play the 'mother' figure for her partner and, thus act as an ideal 'mirror' (as purported by Kohut in 1971) reflecting to her partner appreciation, acceptance and attention (Mitchell, 1989). This is seemingly positive, comforting and enjoyable for the female lovers involved.

Due to the prescription of a rigid set of rules for males in early socialization, Chodorow asserts that adult males are not as able as women to have a flexible definition of masculinity and are not as comfortable with the same level of closeness and intimacy 
as women who experienced a flexible set of rules for their gender orientation in seeing themselves as connected and the same as the mother figure. Men, on the other hand, must rigidly separate from the mother in order to identify with the father figure and, thus, uphold a rigid set of rules or general social expectations for masculinity (Chodorow, 1978). It makes sense then, although contrary to the lesbian "urge to merge," that women in heterosexual couples often struggle to create more intimacy with their male partners and usually maintain a sense of intimacy with close female friends, while men often fear the loss of their autonomy and individual space. The difference in gender role socialization between men and women that is incorporated within heterosexual couples suggests high boundary maintenance, which acts to balance the two relational trajectories of togetherness and separation (Hornstein, 1996). Thus "...If women are socialized to merge, then two women in relation would promote this relational stance by virtue of gender learning" (Hornstein, 1996, p. 11); accordingly, female couples do not only reflect, but emphasize the societal relational roles prescribed to them.

Merger as pathology. Mencher (1997) characterizes the psychodynamic argument for merger-as-pathology as resting on the basic premise that "life begins in a state of symbiotic merger with mother, development consists of a series of progressive disengagement from this (and subsequent) relationships, and fusion in adulthood represents regression to an infantile state of merger and therefore must be held at bay" (p.6). She surmises that this has acted as the foundation for the subsequent generalization of merger as pathology in lesbian relationships. Traditional psychodynamic theorists posit that the intense emotional connections between female 
lovers, paired with sexual arousal and similarities in physical attributes found in lesbian relationships, create, for the women involved, an "unconscious re-connection to the primal relationship with the mother" (Carroll, et al., 1999, p. 53). Because this reconnection to the mother indicates "regression to an infantile state" of symbiosis prior to the process of separation, psychodynamic theorists speculate that such a dynamic in an adult romantic relationship is also regressive and, thus, unhealthy.

Numerous authors have provided support based on clinical populations for the psychodynamic view that women in relationships with women demonstrate evidence of pathological merger. As described by Berg-Cross (1988), the challenge begins when both partners must overcome the obstacles of a dual "coming out" developmental task. In the face of a hostile environment, lesbians are often conceptualized as isolating themselves from the world in a "two-against-the-world posture" (Causby, et al., 1995, p. 68). Despite couples' self-report of relationship satisfaction, several early researchers (Burch, 1982; Elise, 1986; Krestan \& Bepko, 1980; Pearlman, 1988; Peplau, et al., 1978), have noted extreme levels of merger in lesbian couples and have cited the level of dependence as problematic and, thus, lesbian relationships as dysfunctional. Among these concerns is discussion about the destructive effects of dependence, ramifications upon individual self-esteem, stunted ego-development, lack of individuation, and underdeveloped conflict-resolution skills. Accordingly, the merged couple, whose primary focus is the relationship, is perceived as denying differences and avoiding conflict rather than resolving differences and calming tension (Krestan \& Bepko, 1980; Pearlman, 1989). 
Since the psychodynamic definition of merger describes a sense of oneness experienced between two people, adult relationship patterns that portray this characteristic are perceived to have blurred ego boundaries where the identities of the individuals involved are lost and replaced by the identity of the relationship itself (Pearlman, 1989). It is theorized that in this relationship pattern each partner finds it arduous to differentiate her own thoughts, feelings and/or actions from that of the other (Burch, 1985, 1993; Green, 1990; Causby, et. al., 1995; Krestan \& Bepsko, 1980; Pearlman, 1989; Peplau, Cochran, Rook, \& Padesky, 1978). As observed by Burch (1993) in her clinical practice, these partners frequently suffer from a lack of autonomy and independence from one another. Further, prolonged involvement in such a relationship pattern can have serious negative ramifications for both the individual's sense of self and for their satisfaction with the relationship (Burch, 1993; Pearlman, 1989).

Pearlman (1989) illustrates one perspective of merger-as-pathology which emphasizes that prolonged merger requires individual compromise and a loss of self. Therefore, anger, feelings of powerlessness, and low self-esteem may result from this loss of self within the individual. Taking from Chodorow's (1978) theory about female socialization, Pearlman (1989) theorizes that the maternal expectation of sameness between mothers and daughters tends to create negative reactions to individuality and difference. In reaction to her daughter's differentness, the mother becomes emotionally distant, which is continuously interpreted by the daughter as rejection and relationship loss. Consequently, the female child learns to prevent this by a compulsive responding to the needs and wishes of others and a loss of the primacy of one's own feelings and 
desires. Ultimately, independence, autonomy, and individuality can become associated with betrayal and loss of others and, thus, recognized as interferences in emotional connectedness (Pearlman, 1989).

Later gender role socialization asserting female dependency, negating of the self, and constant implied responsibility for the happiness and caretaking of others reinforces these learned behaviors of early childhood (Pearlman, 1989). Therefore, according to Pearlman (1989), in a lesbian relationship, when one partner attempts to assert emotional distance, the other partner interprets this attempt for more independence as disapproval and experiences the emotional distance as a loss. Further, in a relationship of pathological merger in the face of physical or emotional distance, the couple may experience acute tension and/ or anxiety as well as confusion about differentiation of emotional belonging to each partner. Increasing isolation may prevent partners from connecting with outside friendships which, in turn, may create a sense of anxiety at the indication of any instability within the relationship. With the extreme level of compromise and loss of autonomy, the resulting sense of loss of self, or sense of a fraudulent self, potentially turns into resentment and many times depression. The fear of becoming completely engulfed by the other partner or subsiding to extreme levels of dependency can lead one to manifest distancing behaviors. This, in turn, enacts the cycle of rejection that is so closely related to the mother-daughter struggle for independence (Pearlman, 1989).

Systems Approach 
Prominent family systems theories, such as structural family therapy, popularized by Minuchin and Bowen have also perpetuated a pathological perspective about merger in lesbian couples. Both theories contend that healthy relationships among family members and couples rely on differentiation of the self. Critics of these theories have exclaimed that such qualities as individuation and separation are representative of male development whereas those characteristics proposed by these theories to be dysfunctional, such as dependency, emulate qualities typically attributed to women (Green, Bettinger, \& Zacks, 1996).

Concisely, Minuchin's theory of healthy family functioning values firm boundaries between family members with enough flexibility to balance autonomy and interdependence. Minuchin's blending of intrusiveness and enmeshment with closeness and caregiving is particularly difficult for women who value and are orientated towards interdependence. Consequently, enmeshment and disengagement are perceived to result in couple dysfunction (Minuchin, 1974). Similarly, Bowen's (1978) theory of family emotional system values favors differentiation of self over enmeshment. Differentiated characteristics include the assertion of one's self, emotional intimacy without the loss of autonomy and lack of excessive emotional reactivity. Comparatively, undifferentiatied people, according to Bowen, are relational, desire love and approval, and act in service of others. Critiques point out that these are all traditionally female traits. Bowenian theory asserts that the consequences of enmeshment are severe and semi-permanent, including over-emotional reactivity resulting in conflict, emotional distance between partners, triangulation, and/ or some mental or physical dysfunction in at least one partner (Bowen, 1978). 
Green and Werner (1996) further develop this point:

...family therapy's tendency to equate closeness-caregiving and enmeshment was fueled by androcentric, European/ American, middle class ethnocentric models of mental health, which place comparatively lower value on closeness and caregiving (and higher value on individual's separateness and self-sufficiency) in family relations (Green \& Werner, 1996, p. 130).

Thus, based on the male conceptualization of healthy relationships that is essentially grounded in the foundation of separation, merger has been presented as a dysfunctional relational pattern that is pathological for the individual (Mitchell, 1988).

\section{Ego Syntonic/Social Constructivist Approach}

Contrary to psychodynamic and family systems approaches, other theorists have asserted that connection is both vital to growth and the cornerstone of healthy relationships (Burch, 1985; 1993; 1997; Chodorow, 1978; Mencher \& Slater, 1991; Miller, 1976; Surrey, 1985). Women, in particular, seem to prefer intimacy patterns that emphasize connection, rather than disentanglement, These theories suggest that the closeness found in lesbian couples does not have to define nor pathologize their relationship.

Mencher (1997), a Stone Center theorist, has been at the forefront of the struggle to de-pathologize the notion of merger in lesbian couples. She describes merger as egosyntonic and, thus, attuned with the way in which women view themselves and their female role in the world. In this way Mencher (1997) has re-framed the intense intimacy and connectedness used to describe merger as relational strengths. Further, based on relational theory developed by Stone Center theorists, Mencher (1997) asserts that relatedness, as opposed to separation, is the basis for women's self experience and psycho-social-emotional development. Using this theoretical framework, Jordan (1997) 
describes relational health as being rooted in "mutual engagement, mutual empathy, mutual empowerment, and relational authenticity as opposed to the separateness of the self" (Salisbury, 2003, p.12). By using relational theory to deconstruct merger and reinterpret its role in lesbian relational patterns, Mencher has successfully begun the process of de-pathologization of merger as it is applies to lesbian relationships (Mencher, 1997).

Borrowing from Kohut's (1971) Self Psychology, Mitchell (1989) and Stern (1983) conceptualized a healthy relationship, regardless of sexual orientation, based on the degree to which an individual is able to maintain fluid boundaries, or a "permeable self" (Mitchell, 1989), in the face of the "loved object" (Mitchell, 1989). In a relationship, then, each partner forms an attachment to the other, and therefore, takes each other as a self-object. Thus, if self boundaries are permeable and flexible, then "the loved object is both a separate person and is also represented inside the psyche as a 'self-object' that performs important intrapersonal psychological functions" (Mitchell, 1989, p. 158). The term given to this kind of healthy flexibility in interpersonal boundaries is flexible merger (Mencher, 1997). Kohut (1971) as well as Burch (1985) and Mitchell (1989), among others, regard this fluidity as essential for personal growth (McKenzie, 1992; Mencher \& Slater, 1991; Mitchell, 1988). In light of this flexible merger, it seems possible that female couples who have been theorized to exemplify fluidity in their self boundaries are not only capable of intense emotional closeness, but that this can be a healthy component to the relationship and one that promotes personal growth as well. Burch $(1982,1985)$ further explained that because women have more flexible ego boundaries, the state of merger is a natural consequence of pair-bonding 
between women and possibly a relational state that is most conducive to women's personal growth.

Still other theorists, surprisingly similar to Chodorow (1978), highlight the unique features of female socialization and the power of gender roles to explain the disproportional appearance of merger in lesbian relationships. These theorists, Kirkpatrick (1991), McKenzie (1992), Slater (1995), among others, maintain that women are socialized to have a greater capacity for empathy, be attuned to other's needs, be nurturing, not assert individual needs and have relational values more so than men. Thus, these attributes become obstacles for women in attaining the male orientated relational foundation of separateness. Vargo (1987) comments that two individuals following these socially prescribed "rules together may very well become involved in a circular process of orientating self toward the other" (p. 165). Specifically, Pearlman (1989) asserts that merger is the result of a lesbian couple becoming caught in the first stage of their relationship, what she calls "limmerance", which is marked by an intense pre-occupation and longing for one's new partner. As Hornstein (1996) points out, "healthy women" in Western culture are those that are able to focus on and care for others, despite full time employment away from home or flourishing career; "healthy women" maintain the home and family above all other responsibilities. Therefore, two merged women who care for each other "could be reflective of gender training exaggerated by a same-sex pair" (p. 9).

Pardie and Herb (1997) conclude that the greater occurrence of merger-related issues presented by distressed lesbian couples in therapy could be better accounted for by "a crisis-specific artifact of clinical observation- the symptomatic expression of 
failed coping in an otherwise close and committed relationship, but not necessarily the precipitating problem itself" (p. 53). In this way the onus of the framing of merger as pathology in lesbian couples is on the clinicians themselves. Further, Pardie and Herb (1997) recommend that clinicians ask, "what does this conflict represent given the stage of this particular couple's relationship, their individual relationship skills and expectations, and the external stressors they face?" (p. 53). In this light, merger is viewed more as a nonspecific symptom of relationship distress with a complex and varied etiology rather than the cause of relationship issues. These authors also conjecture that merger may simply be the result of several coexisting and precipitating factors that encourage relational conflict to ensue.

In addition to acknowledgement that emotional closeness can reflect maturity in a relationship, a handful of theorists and researchers (Biaggio, Coan, \& Adams, 2002; Colwell, 1988; Green, 1990; McKenzie, 1992; Mencher, 1997) have referenced a multitude of other, less pathological, possibilities to explain very close relationships between same sex couples. Situated within a societal/ cultural perspective, Krestan and Bepko (1980), among others (Barranti, 1998; Berg-Cross, 1988; Causby et. al., 1995; McKenzie, 1992; Slater, 1995), posit that excessive closeness within lesbian couples is the product of surviving in a heterosexist culture, a defense against stigmatization, isolation, and lack of social visibility. These authors maintain that social stressors such as unemployment, child custody, and concerns for physical safety that result from antigay and lesbian sentiments encourage gay and lesbian couples to take refuge with each other and seek validation and support of the relationship that they otherwise do not receive from the larger society (Krestan \& Bepko, 1980). Krestan and Bepko (1980) 
argued that the lack of social support for lesbian couples induces the necessity for the partners to turn inward (i.e., merge) for safety and security in a society that neither validates nor bolsters their relationship. In this conceptualization, society is held responsible for failing to reinforce lesbian relationships in the same way that it sustains heterosexual relationships by its cultural norms, rituals and sanctions. Thus, lesbian relationships do not benefit from the scripts provided by society to prescribe "acceptable" relationship patterns, and women in lesbian relationships find themselves depending on the relationship for support rather than other sources afforded to heterosexual couples (Mitchell, 1989).

Moreover, as McKenzie (1992) points out, in the absence of social support, rituals, legal sanctions, affirmation of the relationship and its boundaries, or traditional milestones, lesbian/gay/ bisexual (LGB) couples must depend on the integrity of their relationship to create and uphold these standards. Thus, merger may be defined as a strategy used to establish and re-establish the couple as safe, together and stable in the face of ostracization, isolation, and lack of relationship models (Causby et. al., 1995; McKenzie, 1992). In their writing about therapy for lesbian couples and the ramifications of a homophobic society, Baggio, Coan, and Adams (2002) explain that merger may strengthen lesbian identities rather than destroy them "in a culture that largely negates their existence" (p. 134). Thus, such perspectives focused on the social construction of individual realities propose that merger in lesbian couples has been upheld as a ramification of a homophobic and heterosexist society.

Some researchers believe that it is the very confusion of the field about the terms merger, fusion and enmeshment that leave women vulnerable to misdiagnosis and 
pathological connotation due to "women's normative development [being] oriented towards caregiving, closeness, and cooperation" (Roper, 1997, p.11-12). The inconsistent research and discussion surrounding the very term merger complicates the pursuit to clearly understand it. Terms that carry negative connotations from the psychodynamic literature of over-dependency and loss of individuality in romantic relationships between women may be responsible for the misconception that all romantic relationships between women are unhealthy (Green \& Werner, 1996; Roper, 1997; Smalley, 1987). Given its complicated composition and multifaceted influence on several realms of interpersonal life, merger, is a difficult concept to understand. It is hard to place it in any one particular sphere of intimate relationships or under any one psychological dimension of relationships.

Empirical Findings of Closeness (Merger) in Lesbian Relationships

Empirical research on closeness of merger in lesbian couples is scant. Nevertheless, the few studies presented here help to evaluate the abundance of theorization found in the field and better suggest the actual prevalence of the phenomena of merger-as-pathology in the non-clinical lesbian population. The results of the research conducted to date are incongruous and vary according to the researchers' conceptualization of the merger as a construct- a dimension inconsistently defined and evaluated without reliable or valid measures specific to any one theoretical framework or the construct of merger in general.

Pardie and Herb (1997) highlight that past theorization about merger was for the most part based upon clinical samples and anecdotal clinical works and then generalized to non-clinical populations. As a result of this and a lack of reliable and 
valid findings on merger (most likely due to its complexity), the initial conceptualizations of merger have stigmatized lesbian relationships with evidence of such negative ramifications as excessive dependency, loss of identity, fears of losing one's autonomy, and/ or sacrifice of the individual for the partnership. In her study of lesbian couples, Roper (1997) cites the debate in psychology about the definitions, origins, and utility of such constructs as enmeshment (i.e. merger) and differentiation. She explains that processes such as "merging ego boundaries" that occurs at an "intrapsychic level" are difficult to study and operationalize (Roper, 1997, p.11).

Contradictory to the concerns previously highlighted, Causby et. al. (1995) surveyed a non-clinical sample of 275 lesbians about the extent of fusion (merger) in their relationships and found that the extent of fusion (merger) was moderate and not excessive. However, those participants who did report high "sharing fusion" were more likely to also report more relationship conflict and inferior conflict-resolution skills. In a qualitative exploration of resiliency in ten lesbian couples, Connolly (2005) found that although couples were satisfied with their level of closeness, they were often frustrated by the pathologizing of their relationship as "too close" or "co-dependent" (p.275). She noted that having a separate career from one's partner was integral in providing participating couples with a healthy relationship balance and opportunity for a separate sense of identity. Connolly also points out that a

healthy dependency offers a context for growth, development, and relationship enhancement... intimacy [is] functional and necessary ...Rather than fusion being 'what's wrong' in lesbian relationships, this data suggest that it instead might be part of 'what's right' in the relationship...Empathic capacity and autonomous capacity might be developed and revealed simultaneously, allowing for an enhancement of 
intimacy and a clear sense of self that is distinct from the relational partner (p.275).

Another qualitative study of eight non-clinical lesbian couples by Hill (1999) explored fusion and conflict in lesbian relationships and found that fusion was not characteristic of lesbian relationships in general, but could be an issue which arises for couples in psychotherapy.

Other research findings seem to highlight the positive aspects of closeness in lesbian relationships and the positive ramifications of this closeness for the partners involved as well. Blumstein and Schwartz's (1983) ground-breaking study of American couples is one of the most influential studies of relationships and perhaps the single best contributor to what we know of the texture and patterns of lesbian couples. The sheer magnitude of the study, gathering over 12,000 questionnaires from a diverse range of geographic locations, as well as the diverse use of couple types including married, nonmarried cohabitating, and same sex, greatly contributed to the existing literature of the early $1980 \mathrm{~s}$. Of the 12,000 returned questionnaires, 3,600 married (heterosexual) couples, 650 non-married cohabitating heterosexual couples, 957 gay male and 772 lesbian couples were included in the study. From these couples, 72 married couples, 48 cohabitating heterosexual couples, 90 gay male and 90 lesbian couples were interviewed. The questionnaires and interviews covered a broad range of topics from couples' relationship history, to attitudes and feelings about their relationships and relationships in general, to emotional support, money, sex, conflict, housework, leisure time, and time with family and friends.

While significant finding are still influential in the clinical literature today, the severe under-representation of minorities (95\% White and 1\% each Black, Asian, Asian 
American and Latino) and residents of rural areas, as well as the attitude shifts over the past 20 years, significantly date this study. Nevertheless, these authors did find that all couple types, with the exception of lesbian couples, balanced power according to the amount of money each partner earned. Moreover, negative feelings about financial status negatively affect feelings for each other in all but lesbian couples. Blumstein and Schwartz (1983) suggest that this finding is due in part to the non-central role of earning power in women's identities as well the higher value placed on egalitarianism by lesbian couples. Contrary to claims about lesbians' inclinations toward merger or fusion, these authors found that lesbians felt that in order to be interdependent they must first each be independent.

Further, lesbian couples had the greatest percentage of mutual relationship orientation ( $41 \%$ versus $25 \%$ for married couples, $30 \%$ for cohabitators and $27 \%$ for gay men) and overall, those couples in which both partners were relationship-centered were found to be the happiest and most committed. Lastly, lesbians of all ages were found to desire more time together compared to males (gay and heterosexual) who reported needing independence as young men and progressively valuing companionship as they aged. The common interests of same-gender couples and shared experiences on the basis of gender may also account for the increased capability for partners to fulfill needs of both friendship and romantic love in lesbian and gay male couples. Overall, the findings of Blumstein and Schwartz (1983) support relational theorists who posit that in lesbians couples, self-other differentiation can and often does exist along with high levels of closeness and relationship satisfaction (Salisbury, 2003). 
Several studies (Duffy \& Rusbult, 1986; Kurdek \& Schmitt, 1986; Peplau \& Cochran, 1983) in which lesbian, gay male and heterosexual couples are compared have found support for no or minimal differences in relationship satisfaction among these couple types. However, three of Kurdek's $(1988 ; 1991 ; 1995)$ studies of lesbian couples point to differences in relationship satisfaction. Results from his 1991 study of 75 gay male and 51 lesbian couples showed that lesbian couples reported more rewards from their relationship in comparison to gay men. In 1988, Kurdek reported higher relationship satisfaction among cohabitating lesbian couples compared to cohabitating gay male couples. In 1995, Kurdek concluded that these discrepancies are related to gender differences in the value placed on relationships. In addition, a longitudinal study by Kurdek in 1998 comparing lesbian, gay male and heterosexual couples found that lesbian couples, contradictory to merging theories about lesbians, reported more intimacy yet also more autonomy than heterosexual couples.

In her dissertation study, Salisbury (2003) also found that overall, the 87 lesbian couples in her sample reported more relationship and sexual satisfaction than a comparative sample of heterosexual women. Salisbury reports that this higher relationship satisfaction was predicted by greater emotional intimacy and high cohesion. Further, she concludes that not only do these findings contradict claims of pathological merger (she refers to this as fusion) as indicated by Krestan and Bepko (1980), but "there is no such thing as too much closeness when it comes to relationship satisfaction among lesbian couples" (Salisbury, 2003, p. 104). However, some results suggest that lesbian couples were more prone to merger as theorized by Bowen (1966) in that they avoided conflict which resulted in less relationship satisfaction (Salisbury, 2003). 
Also concerning relationship satisfaction, Green, Bettinger, and Zacks (1996) used the Family Adaptability and Cohesion Scale (FACES; Olson, Sprenkle \& Russell, 1983) to assess lesbian, gay male and heterosexual couples. They found lesbian couples to be significantly more satisfied with their relationship than heterosexual couples. Additionally, $79 \%$ of lesbian and $56 \%$ gay male couples reported very high flexibility with either very high or moderately high cohesion versus only $8 \%$ of heterosexual couples. While these results confirm the expectation that lesbian couples would be the most cohesive of the three couple types, these findings also defy traditional gender socialization theory in that gay males are expected to be the most disengaged; in fact, gay male couples in this study reported more cohesion than heterosexual couples. This sample was a more diverse sample than those used by previous studies. Participants ranged in age from early 20 s to 80 s and were racially $84 \%$ White lesbians and $88 \%$ White men, although mainly college-educated. Similarly, Schreur and Buunk (1996), in a study of 119 Dutch lesbian couples, found that couples with the highest degree of closeness also had the most relationship satisfaction. These authors concluded that emotional dependency, rather than intimacy hindered autonomy in relationships (Salisbury, 2003). Anderson (1989) found that among a sample of 72 lesbians and 67 heterosexual women in committed cohabitating relationships, lesbians reported significantly higher levels of intimacy, although levels of relationship satisfaction and merger were not found to differ between the groups.

Roper (1997) was one of few studies to include the variable of outness in her investigation of female couples. Among a sample of 141 women, Roper found significant correlations between respondents' individual functioning (i.e., 
psychological adjustment, social support, and outness) and their perception of their partners' relationship behavior. Partners' perceived cohesion and differentiation were positively related to respondents psychological adjustment, and correspondingly, partner's merger as measured by the intrusiveness subscale of the California Inventory of Family Assessment (CIFA; Werner \& Green, 1989) was negatively related. However, social support seemed to moderate partners' merger, although "outness" was found to be independent of all three variables (Roper, 1997).

Carroll and Gilroy (1993) also focused on partners using qualitative interviews and found that in talking about incidents of closeness and connectedness with partners, participants distinguished between sexual, cognitive, and emotional experiences of merger with their partner, describing each as positive attributes to their relationship in a larger sense (Carroll, et al., 1999). Using a sample of 190 participants (34 lesbian couples, 31 gay male couples, and 30 heterosexual couples), Carroll et al. (1999) assessed partners' perceptions of relational interconnectedness (measured by The Inclusion of the Other in the Self Scale; Aron, Aron, \& Smollan, 1992) and merger (measured by a series of four questions representing emotional, cognitive and sexual merger as well as frequency of distancing during sexual encounters on a five-point Likert-like scale designed by the authors) and participants' level of ego development (measured by The Washington University Sentence Completion Test of Ego Development; Loevinger \& Wessler, 1970). These researchers found no significant difference between lesbian, gay male or heterosexual couples in relational interconnectedness or frequency of emotional, cognitive and sexual merger. However, 
gay male couples reported significantly more frequent occasions of feeling emotionally and mentally removed during sexual encounters than lesbian couples, but less often than heterosexual couples. Although Carroll, et. al. did not find a significant correlation between ego development and merger, they conclude that couples were "relatively healthy" with "intimate and enduring relationships" (p.65).

Conversely, Berzoff (1989) found that experiences of merger using qualitative in-depth individual interviews among a non-clinical sample of 18 heterosexual women with their closest female friends was correlated to higher stages of ego-development as measured by Loevinger and Wessler's (1970) measure of ego development and their corresponding seven stages of ego development. Accordingly, women who fell in the highest ranges of character development or development of self also experienced qualities of merger in their closest friendships. Berzoff (1989) explained, "empathy and access to the deepest, inner experiences of others require a high level of self differentiation" (p. 105). Therefore, fluidity in self-other boundaries could help sustain and even enhance close interpersonal female relationships. Berzoff (1989) further concluded that "temporary losses of self need not be understood not as regressive or necessarily pathological losses, but as potential articulations of the self in the context of an intimate other" (p.106).

Similarly, Rubin's (1985) study about friendship in 300 men and women uncovered that women's multiple friendships with other women help to define their sense of self. Rubin proffers that women's friendships "...offer a shared intimacy that's quite different from what they experience in a relationship with a man" (p. 66). The presence of merger in multiple types of relationships between women challenges the 
pathological view of merger in lesbian couples in that it suggests that the dynamics between two women in a relationship facilitates merger irrespective of sexual orientation.

In an effort to distinguish between different styles of emotional closeness and assess the "bipolar continuum" (Cowell, 1985, p. 9) of merging and disengagement, Colwell (1985) developed the Emotional Closeness Scale (ECS). The results of giving this scale to 182 undergraduates led Colwell to conclude that the dimensions of merging and disengagement follow a "model of orthogonality" (p.16). Further, as explained by Colwell, the merging items of the ECS mirrored the object-relational definition of merger as "needy dependence" and "ego loss" (p.16). Surprisingly, gender was not found to be a significant predictor of merging or disengagement; however, Colwell attributed this to the young mean age, 19 years, of her college sample, and the short average duration of their relationships.

In 1988, Colwell used another version of the ECS entitled the Merging/Disengagement Scale (1988) to assess gender differences in merging and disengagement in a sample of 26 lesbian, 21 gay male and 28 heterosexual couples (total of 152 individuals). She hypothesized that empathy, merging and disengagement are related constructs and vary according to gender roles. Interestingly, the results of Colwell's study were somewhat contradictory to the clinical literature and her hypotheses about lesbian couples. Lesbians were, surprising, not found to be the highest in merging, but were the lowest in disengagement; consequently, in comparison to other groups, they did not report higher levels of dissatisfaction with autonomy issues 
and they showed that emotional closeness with independence were strengths of the relationship.

Lastly, the qualitative results from a previously conducted focus group study (Golding, 2006) have been used to inform this exploration. During the months of August and October of 2006, two semi-structured focus groups were conducted with three and four women, respectively, in Providence, RI and Boston, MA. All seven female participants were at the time in a monogamous relationship with another woman and had been for at least one year. The mean ages of the Providence and Boston group were 48.3 and 33.2 years, respectively. All participants were White, educated and selfidentified as either lesbian $(n=6)$ or bisexual $(n=1)$. Two participants had been previously married to a man. The mean numbers of years in the current relationship at the time in the Providence and Boston groups were 15.9 years and 1.9 years, respectively.

The following questions were posed to both groups: (1) Some people say that female couples are closer than gay male or heterosexual couples, do you think this is true and why? (2) How do you describe this closeness in your own relationships? (3) Are there different degrees of closeness? How so? (4) Does the closeness in your relationships increase, decrease or change depending on you or your partners out status? How so? (5) Does this closeness have a purpose? If so, what is the purpose? (phase? style? response? strategy?) (6) Does this closeness add to your personal relationships or cause problems or both?

The women of these focus groups reported that they felt women are more capable of emotional intimacy because women allow themselves to be more intimate. 
Both groups attributed this greater pull towards intimacy to women's social roles concluding that women are "trained" to behave according to their respective prescribed gender roles. In defining the closeness that the women acknowledged did exist in their relationships, the groups identified unconditional safety, respect, comfort, reliability, and companionship as some of the key descriptors. Groups agreed that out status does affect relationship; that if one partner is not out while the other is, resentment can build and create conflict in the relationship or an over-dependency that is not healthy. To these women, to not be out is to deny the existence of their relationship. It should be noted that all participants were out to most people in their lives, thus this finding may not represent those women who are not out. Further, the two groups also agreed that female relationships are a natural outgrowth of friendships. The Providence group stated that many of the characteristics these women see in their friendships are also in their romantic relationship. Generally, the groups concluded that the closeness they experienced was most healthy when it was a "flexible closeness." If a couple is too close and it is not flexible, the relationship can break. Further, both groups strongly agreed that it is a problem to allow the relationship to replace one's sense of self. A theme related to the differences between butch and femme couples in terms of individuation also surfaced.

Qualitative results from these groups suggest that merger and intimacy are qualitatively different. Whereas intimacy appears to be most associated with behavior, the closeness identified is experienced as a pattern of relating between partners that greatly adds to the relationship and in some cases defines the essence of the couple's connection. Further, the closeness experienced by female couples with other women is 
positive and healthy so long as a sense of differentiation is firmly in place. Lower levels of emotional autonomy with higher levels of interdependence seems to be most conducive to the natural rhythms of female patterns of relating. Lastly, one's out status also seems to play a role in the degree of closeness and interdependency experienced by the couple.

The research presented here has all called for further evaluation of the conceptual basis for merger. The authors of these studies continually state that the misconceptions, confusions and scant empirical investigation of merger has led to an unjust pathologizing of female couples and a misconstrued understanding of how women relate to one another and, in some ways, to the world and to themselves.

Proposed Model: Model of Healthy Emotional Reliance (HER)

In echoing Burch $(1982,1985)$, who posits that merger is a natural consequence of pair-bonding between women due to more flexible ego boundaries, and a relational state that is more conducive to women's socialized relational styles, it is possible that the shift in focus from the self to the relationship allows a greater sense of relationship satisfaction and larger capacity for personal growth. Therefore, it could be that women actually cultivate more profound levels of intimacy and that this intimacy may be a valuable and healthy rather than destructive or pathological component of the more intense closeness seen between women

This suggests that women in relationships with other women are capable of achieving greater intimacy than women in relationships with men. This greater intimacy may overwhelm some female relationships, but not necessarily prove to be burdensome. Further, it may be that their intimacy serves an adaptive function and is a 
level of understanding of the other and in doing so, attain a fuller understanding of the self as well. Thus, intimacy, it seems, is similar to healthy emotional reliance, although different in that healthy emotional reliance is a consistent pattern of intense, but healthy closeness.

Entrenched within theoretical assumptions about female socialization discussed above, it is reasonable to expect that women in relationships with other women will most likely be more oriented towards the needs of the relationship than heterosexual or gay male couples. Thus, according to social role expectations, a higher degree of emotional intimacy will most likely be experienced by women in a relationship with another woman. Theory proposed by Peplau, et. al. (1978), adapted from Raush (1977), speculates that autonomy and attachment are not polar opposites, but rather separate domains towards which one is capable of being strongly orientated simultaneously. Therefore, the female couple may be able to experience high levels of interdependency while simultaneously valuing and achieving healthy levels of emotional autonomy and self differentiation that are more conducive to the socialized female relational style.

Given this context of female sexuality, socialization and the confusion surrounding the term and clinical significance of merger, the purpose of this study was to introduce a model of healthy emotional reliance using a feminist ego theoretical orientation. As such, this model postulates healthy emotional reliance in female couples as positive, adaptive, healthy, and instrumental to the personal growth of the female individual and the female couple together. So, simply, healthy emotional reliance is not equivalent to intimacy; it is something different, something more than intimacy...an 
actual pattern of relating with closeness and interdependency that is healthy, adaptive, and conducive to emotional autonomy and differentiation.

\section{Interdependency}

\section{HER Model Variables}

The construct of interdependency is conceptualized from Bornstein and Languirand's concept of healthy dependency (2003). Accordingly, healthy dependency is

the ability to blend intimacy and autonomy, leaning on others while maintaining a strong sense of self, and feel good (not guilty) about asking for help when you need it...depending on people without becoming dependent on them...trusting people enough to open up and be vulnerable, yet having the self-confidence you need to survive those inevitable relationship conflicts (p.19).

This construct was used as one of the hypothesized dimensions that underlie healthy emotional reliance.

This study utilized the Healthy Dependency (HD) subscale score of the Relationship Profile Test by Bornstein and Languirand (2003) to operationalize the construct of interdependency that is hypothesized to underlie the dimension of healthy emotional reliance. The ten-item subscale ranges in scores between seven and 70 on a 7-point Likert-scale. An example item from this subscale is "It is easy for me to trust people" (Bornstein, Languirand, Geiselman, Creighton, West, Gallagher, \& Eisenhart, 2003).

\section{Emotional Autonomy}

Much like the term merger, autonomy, too, has been defined by various theorists in numerous ways. As explained by Anderson, Worthington, Anderson \& Jennings (1994), autonomy is a meta-construct, which means that it is comprised of several 
constructs. The four identified by the autonomy literature, according to these authors, are family loyalty autonomy, value autonomy, emotional autonomy and behavioral autonomy. Specific to this study, emotional autonomy represents the ability "to exert self-control, to exercise emotional independence, to achieve interpersonal competence, and to make adequate social commitments" (Anderson, et. al., 1994, p. 330).

In an attempt to remain consistent across terms and measures, this study employed the above theoretical definition of emotional autonomy and used the Emotional Autonomy sub-scale score of the Worthington Autonomy Scale (1994) as an operational definition of emotional autonomy proposed to underlie the construct of healthy emotional reliance.

\section{Differentiation}

The construct of differentiation is conceived based on the theoretical definition of the term according to the Differentiation of Self Inventory (DSI; Skowron \& Friedlander, 1998) authors. Based on Bowen $(1976,1978)$, these authors define differentiation of self as

the degree to which one is able to balance (a) emotional and intellectual functioning and (b) intimacy and autonomy in relationships... On an intrapsychic level, differentiation refers to the ability to distinguish thoughts from feelings and to choose between being guided by one's intellect or one's emotions (p.235).

As the validating studies of the Differentiation of Self Inventory found four distinct dimensions (emotional reactivity, I-position, emotional cut-off, and fusion with others) of a single construct, differentiation of self, this study employed the full-scale score as an operationalized definition of the proposed differentiation of self construct in 
order to adequately assess it as one dimension underlying healthy emotional reliance in female couples (Skowron \& Friedlander, 1998).

\section{Outness}

This variable was theoretically defined as the extent to which a woman discloses her sexual orientation and it was operationally defined by the score obtained on the Miranda and Storms' (1989) Sexual Orientation Disclosure Scale (SODS). Miranda and Storm's (1989) Sexual Orientation Disclosure Scale (SODS) was used to measure degree of outness, the extent to which participants have disclosed their sexual orientation to others. The 15 Likert-type items ask about different types of relationships in which lesbians may or may not be out to others (i.e. To other gay people, To your mother, To people involved with your housing). These items are rated on a seven-point scale with seven indicating the greatest degree of disclosure $(1=$ not "out" to $7=$ completely "out"). This scale ranges from scores of 15 to 105 with lower scores indicating less disclosure and higher scores indicating more disclosure of sexual orientation (Miranda \& Storms, 1989).

\section{Emotional intimacy}

Lichtenberg (1991) suggested that intimacy is the combination and balance of two natural human urges: self-assertion and mergence striving. This definition served as the theoretical base for the investigation at hand. As reviewed by Hook, Gerstein, Detterich, and Grindley (2003), research on the construct of intimacy has identified four features most referenced by theorists: love and affection, personal validation, trust, and self-disclosure. In their construction of the Personal Assessment of Intimacy in Relationships (PAIR) inventory, Schafer and Olson (1981) identified five different 
kinds of intimacy: emotional, social, sexual, intellectual and recreational. Based on early research by Olson based on his Circumplex Model (1979), Olson describes intimacy as a process "that occurs over time and is never completed or fully accomplished" (p.50). In an attempt to test the orthogonality of healthy emotional reliance and emotional intimacy, this study used the PAIR (Schafer \& Olson, 1981) and the HER'S to assess the possible overlap of the two dimensions. Because this study is only interested in the emotional aspect of intimacy, only the Emotional Intimacy subscale score assessing the ability to feel close to someone was used as an operational definition (Schaefer \& Olson, 1981).

Variable Relationships (see fig. 1)

The above variables (Interdependency, Emotional Autonomy, Differentiation, and Outness) included in the proposed model of healthy emotional reliance (HER) were chosen for the specific qualities they represent that were hypothesized to underlie the proposed construct of healthy emotional reliance. Interdependency was chosen as the main variable of the HER model for a number of reasons. As postulated by Bornstein and Languirand (2003), socialization and psychological models have taught us to disconnect, when we need to learn to reconnect. Human connection is a vital part of survival; we are social beings meant to depend on each other, help each other and trust each other as a way to become emotionally connected. In order to have healthy emotional connection, one must be able to open themselves up to emotional vulnerability, yet differentiate themselves from others and maintain emotional autonomy. Therefore, the dimension of interdependency represents the mutual 
connection piece of the HER model that allows two people to depend on one another without suffocating or draining their partner.

Emotional autonomy was chosen as part of the HER model in order to represent emotional independence. Emotional autonomy differs from general autonomy in that it relates specifically to emotional and interpersonal competence. Thus, as the HER model characterizes the healthy relationship between female partners and the interpersonal interplay within a female couple, emotional autonomy was chosen to represent the emotional component within this dyad which is considered by the HER model to be an integral part of the concept of healthy emotional reliance.

Similarly, Differentiation of self is the most critical personality variable to attain mature development and psychological health according to Bowen Theory. Differentiation of self on an interpersonal level combines the ability to experience intimacy with others while simultaneously keeping independence from others. The authors of the DIS explain that the 'I-position' is indicative of a differentiated individual in which one maintains a definite sense of self in the face of pressure to conform to other's identifications. "Differentiation allows for flexible boundaries that permit emotional intimacy and physical union with another without a fear of merger" (p. 235). Poorly differentiated people cope with overwhelming emotions through either fusion or emotional cut-off. While separation overwhelms the fused individual, intimacy profoundly threatens the emotionally cut off person. Nevertheless, they both lack differentiation evidenced by their consistent dependence on the approval of others for feelings of worth and general conforming behavior. 
Interestingly, Skowron and Friedlander (1998) also point out that differentiation is often confused with individuation or autonomy in the family therapy literature. These authors explain that individuation, an object-relations term, refers to independence and the attainment of a unique identity whereas "differentiation of self is the capacity to maintain autonomous thinking and achieve a clear, coherent sense of self in the context of emotional relationships with important others" (p.237). Therefore, differentiation was chosen to represent the dimension of the HER model that allows partners to distinguish themselves from one another and act independently from each other when appropriate.

Given theories about internalized homophobia, out status, and research findings on the integral qualities of social support, this study proposed that the extent to which a woman is out influences the other three constructs of the HER model: interdependence, emotional autonomy, and differentiation. Therefore, outness is included in the HER model as a mediating variable that affects the other three variables.

Due to various social pressures of Western culture, lesbians are placed in double jeopardy, a term used to describe an individual with minority status in two areas of psycho-social functioning, as women and as minorities in their sexual orientation. As such, lesbians face the unique act of voluntary disclosure of their minority status as opposed to racial or ethnic minorities for whom their minority status is generally involuntarily disclosed to others. Lesbians that are also part of an ethnic minority group may find themselves in triple jeopardy, holding minority status in three categoriesgender, sexual orientation and ethnicity. A supportive social environment can be instrumental to the validation and substantiation of a romantic female couple. In some 
instances, the degree of social support may determine the level of merger experienced by the couple. In the absence of social support, the couple may merge, or merge further, in an attempt to create a sense of security amidst an environment that hinders the livelihood of their relationship (Krestan \& Bebko, 1980). Thus, it is possible that, the extent to which a woman discloses her sexual orientation, the degree of her outness, determines the extent of her possible range of social support and, therefore, may influence the vulnerability of merger in her relationship.

The lesbian couple's struggle to maintain emotional intimacy in the face of societal preclusion may intensify feelings of vulnerability and, thus, direct the couple towards merger. As Pearlman (1989) states it, society, with its many obstacles, "profoundly impact[s] the security of the couple formation and may be an important factor in the intensity and prolongation of couple merger in lesbian relationships" (p.77). Kurdek (1988) reports that social support was significantly related to psychological well-being in her sample of 50 lesbian couples. Further Olson (1988), in a sample of 130 lesbian couples, found social support to be the single best predictor of psychological well-being (Roper, 1997).

Theories presented by Pearlman (1989) and Burch (1982) explain that lesbian couples experience difficulties as they both face varying degrees of ambivalence about the difficulties imposed by a lesbian lifestyle and the frustration, anger, and ambivalence about "lesbianism can be unconsciously directed towards one's partner" (Pearlman, 1989, p. 86). A study by Bradford, Ryan, and Rothblum (1994) surveyed 1,925 lesbians and reported that $88 \%$ of the participants were out, but to varying degree of different groups of people such as co-workers (17\%), all family members $(27 \%)$, and 
heterosexual friends (28\%; Roper, 1997). As Pearlman (1989) further theorizes, the act of continuously "passing" for heterosexual may impede the socialization and validation of a lesbian couple and, thus, increase their isolation which, in turn, furthers the perpetuation for the couple to merge.

Several authors, such as Barranti (1998), Garnets and Kimmel (1993), Patterson (1995) and Peplau and Garnets (2000), among others, have discussed the implications of internalized homophobia, in which the gay male or lesbian experiences feelings of guilt, shame, and anxiety about their sexual orientation; a literal internalization of the fears and prejudices of the dominant culture. Internalized homophobia has been described as the most hurtful and insidious stressor that the lesbian couple faces because it can be and often is largely unconscious. Self-disdain, low self-esteem and shame, not only shadow one's experience of self, but also uncover underlying doubt in the viability of the romantic partnership, and thus disrupts trust in the relationship (Barranti, 1998).

This may further intensify the relationship and may cause fears of overdependency and engulfment in the not-"out" or somewhat-"out" partner, as well as, resentment in the "out" partner who wants the relationship to be public and celebrated. Similarly, even if a partner is "out," as discussed by Pearlman (1989), resentment about the difficult tasks this encompasses within a society that largely negates the existence of lesbian relationships can cause projected resentment and anger imbedded within the relationship on the account of both partners.

Further, a partner who is not out severely limits her access to social support and may over-rely on her partner to be the sole embrace of the "real" her and may only be able to feel able to envelop all of herself with her partner. Hill (1999) found support for 
this notion in her qualitative study of eight lesbian couples. She noted that conflict around fusion arises in the presence of resentment about family isolation (in the case of family rejection due to non-acceptance of the same-sex relationship or, more likely, not being "out" to one or both partners' families). In this case, an exceptionally strong and exclusive dependence on the relationship by one partner results in overwhelming pressure on the other partner who may struggle to cope with this pressure and may ultimately withdraw and/or attempt to leave the relationship consequently causing conflict.

\section{Hypotheses}

Based on previous research and the plethora of theoretical literature as well as a previously conducted focus group study by this author, the following hypotheses were posed:

Hypothesis 1: the Healthy Emotional Reliance Scale will be comprised of four factors which constitute the experience of healthy emotional reliance in female couples: interdependence; emotional autonomy; differentiation; and relationship satisfaction. Hypothesis 2: construct validity can be established for healthy emotional reliance by demonstrating correlations with variables expected to be positively related: interdependence, measured by the Relationship Profile Test, emotional autonomy, measured by the Worthington Autonomy Scale; and differentiation, measured by the Differentiation of Self Inventory. Discriminant validity can be established for healthy emotional reliance by demonstrating a non-significant relationship between the HER'S total score emotional intimacy, measured by The Personal Assessment of Intimacy in Relationships Inventory. 
Hypothesis 3: a significant positive relationship between the degree of outness, as determined by the SODS, and healthy emotional reliance, as measured by the HER'S, will exist for individual women who are currently part of a female couple.

Hypothesis 4: there will be a positive significant correlation between the level of healthy emotional reliance, as measured by the HER'S total score, and degree of satisfaction with a current relationship, as measured by a sub-set of relationship satisfaction items on the HER'S, for individual women who are currently part of a female couple.

\section{Methods}

A set of 50 items was developed to measure healthy emotional dependency. The items were developed from specific issues raised by women in previously conducted focus groups, consideration of Colwell's Merger/ Disengagement Scale (MDS; 1988), and other appropriate sources based on the respective literature and consultation with experts such as committee members. Items were written at a fifth grade reading level, with no double negatives. One item was reverse scored and order effects of items must be taken into consideration.

\section{Participants}

In order to establish initial validation of the HER'S and test the four hypotheses previously presented, 430 adult women currently in a relationship with another woman for at least the last 12 months were solicited through advertisements in national lesbian/gay/bisexual (LGB) and feminist internet networks and lesbian/ feminist social/ support/ community groups and university list serves across the United States.

Consistent with previous research (Carroll, et. al., 1999; Gregory, 1999) participants 
were recruited using the snowball (chain) sampling procedure in which participants were asked to provide the study's online survey link url to other potential participants who meet the study's eligibility criteria.

Invitations to participate were posted to online list serves such as The Psychology of Women Resource List (POWR-L), a free online list-serve co-sponsored by APA 35 (Division on Women) and Association for Women in Psychology (AWP), for the discussion and dissemination of information about the psychology of women. In addition women's groups and social circles of the South Lake Tahoe, California, Boston, and Providence areas were also contacted concerning participation in this study. The researcher knows several people involved with social groups in the Tahoe, San Francisco Bay area, Boston and Providence areas who helped with recruitment of eligible participants.

\section{Inclusion/ Exclusion Criteria}

Eligibility criteria included women 18 years and older who are currently involved in a sexual, monogamous relationship with another woman for at least one year. According to Mencher and Slater (1991) and Slater (1995), one year is the minimum amount of time necessary for a couple to establish themselves as a family system and for difficulties related to merger to manifest. Other researchers have chosen less stringent criteria, such as the participation in a lesbian relationship in the last six months (Causby, et. al., 1995) or more narrow requirements like cohabitation for at least two years with no experience of couples therapy (Carroll et. al., 1999). The criterion chosen for this study was adapted from previous studies (Blyth \& Straker, 1996; Barranti, 1998; Hill, 1999) suggesting that merger characteristics do not have the 
chance to manifest before one year reflecting the focus and intentions of the research at hand. It was not essential that participants identify as lesbian, in fact, participants could have identified their sexual orientation however they saw fit; this study concentrated on the relational patterns women exhibit with their female partners rather than labels that are given by society, partners, or the individual themselves.

Additionally, participants must have been able to read and write English (at a fifth grade reading level or above), otherwise participants could have been of any ethnicity. It is impossible to seek a representative sample because the population distribution of lesbians is not known, and the population of women who may not identify as lesbian or bisexual but are in relationships with other women is all the more unknown. Thus, participants were recruited from diverse parts of the country via the internet and from a variety of settings (classified advertisements, newspaper announcements, flyers, GLB centers, online list servers and friendship networks). Both partners of the couple were eligible to participate. All participants were aware of the nature and purpose of the study: to increase the understanding of female relationship experiences. All participants of the study were volunteers and no compensation was offered.

\section{Procedure}

Pilot Study. The initial 50 item scale was reviewed by thirteen readers (both in the psychology field and out of the field) independently in order to assess comprehension, maximize clarity, and eliminate ambiguity. Five female psychology graduate students served as peer reviewers to gain expert feedback on the wording and clarity of the HER'S items. Two of these peer reviewers completed the entire set of 
measures online for length assessment and time limits. In addition, eight women in relationships with other women from the local community were recruited to complete the HER'S items only and provide their reactions to the wording and clarity of the items. The final item pool was selected based upon clarity, content appropriateness, length of the measure and minimization of redundancy.

Main Study. The resulting 50 item pool was validated and tested for reliability using a sample of 368 participants via an online survey. Participants completed an online anonymous survey through surveymonkey.com. Online surveys were posted via a webpage link on popular lesbian/ women list-serves. Participants were given a web address and led to the study's questionnaires. All web pages were linked together as a single survey so that forms from each participant remain together for data analysis purposes. Surveys, however, were not connected to any IPC addresses and information was transferred using an encrypted link in order to protect confidentiality.

Consent was implied via a disclosure statement asking participants to confirm that they are at least eighteen years old, understand that their participation is voluntary, the length of time commitment anticipated to fill out questionnaires, that their completion of the questionnaires indicates their consent to participate, they will not receive any compensation, all information is anonymous, that their name will not be identified at any time, and that they have the right to examine the overall research results and any conclusions drawn from the results (see Appendix D).

Participants were given the researcher's name, phone number, e-mail and physical address should they want a summary report of the study. These procedures helped maintain anonymity. No attempt was made to identify participants. 
Measures (see Appendix C)

Along with the developed intial 50 items, the following six scales and one demographic sheet was completed by participants. Relationship Profile Test (RPT; Bornstein \& Languirand, 2003), The Worthington Autonomy Scale (WAS; Anderson et al., 1994), and The Differentiation of Self Inventory (DSI; Skowron \& Friedlander, 1998), and were included in order to provide construct validity for a different hypothesized components of the developed scale: interdependency, emotional autonomy, and differentiation. The Sexual Orientation Disclosure Scale (SODS; Miranda \& Storms, 1989) measured outness and was used to assess the relationship between the degree of outness and healthy emotional dependency. The Emotional Intimacy subscale of the The Personal Assessment of Intimacy in Relationships (PAIR) Inventory (Schaefer \& Olson, 1981) was used to provide divergent validity for the constructed measure of healthy emotional dependency, distinguishing between intimacy and healthy emotional dependency as it is experienced in female romantic couples. Lastly, the Merger/Disengagement Scale (MDS; Colwell, 1988) was used to provide discriminate validity between merger and healthy emotional reliance. In addition, one qualitative item was added to the end of the survey asking participants: What does healthy emotional reliance mean to you? The total number of questions asked of participants from measures was 173 all together.

The Demographic fact sheet asked for age, ethnicity, gender (how one identifies), public and private sexual orientation, highest earned degree, occupation, number of months in their current relationship, if they cohabitate with their partner, if so, the amount of time that participants have cohabitated with their partner, if 
participants had children, if so, number of children living in the household currently, their ages and how long they lived with the couple and if their partner was also participating in this research. The total number of demographic questions was 15 questions.

Relationship Profile Test is a 30-item self-report measure of dependency detachment that yields three 10-item subscale scores: (a) destructive overdependence (DO), (b) dysfunctional detachment (DD), and (c) healthy dependency (HD). This study used the RPT to measure interdependency in female couples for this study. Statements were written to tap into the four components of each personality style: cognitive, emotional, motivational, and behavioral. Participants respond to statements on a 7-point scale ranging from "not as all true of me" to "very true of me" and scores range from 30 to 210 with lower scores on the DO and DD subscales representing healthier attachment styles and higher scores on the HD representing higher degrees of healthy dependency. Representative samples from each subscale include: "Being responsible for things makes me nervous" (DO), "Other people want too much from me" (DD), and "It is easy for me to trust people" (HD; Bornstein, et al, 2003).

Using a sample of 130 undergraduates ( 75 women and 55 men), Bornstein et. al. (2003) obtained reliability and validity psychometrics as well as 23 week and 85 week re-test reliability scores (using separate samples of fifty, 25 women and 25 men, participants one from the initial sample and the other from pre-screened, but uninvolved in study so far, for each follow up test session). These authors found the RPT subscales to have sufficient internal reliability $(\mathrm{DO}=.83 ; \mathrm{DD}=.68 ; \mathrm{HD}=.75)$ and adequate intercorrelations between the three subscales $(\mathrm{DO}-\mathrm{DD}=.00 ; \mathrm{DO}-\mathrm{HD}=-.32$; 
$\mathrm{DD}-\mathrm{HD}=-.46$ for women and $\mathrm{DO}-\mathrm{DD}=.10 ; \mathrm{DO}-\mathrm{HD}=-.34 ; \mathrm{DD}-\mathrm{HD}=-.37$ for men $)$.

Once four items from subscale DD and two items from subscale HD that correlated below .50 were dropped (creating a truncated RPT of 24 items), coefficient alphas increased for DD and HD to .80 and .84 respectively.

With the exception of one correlation $(\mathrm{r}=.71)$, all predicted RPT-comparison scale score correlations were in the $.25-.50$ range. By way of convergent validity effect sizes, the authors determined that "the truncated version of the RPT was less strongly correlated with relevant outcome measures than was the full version of the scale" (Bornstein, et al, 2003, p. 69). Retest reliability Pearson coefficients for the full scale RPT are .65 for $\mathrm{DO}, .75$ for $\mathrm{DD}$, and .41 for $\mathrm{HD}$ for the combined sample at the 23 week follow-up and .65 for $\mathrm{DO}, .55$ for $\mathrm{DD}$, and .48 for $\mathrm{HD}$ for the combined sample at the 85 week follow-up (when not corrected for moderating effects of daily hassles and life events).

Bornstein, Geiselman, Eisenhart and Languirand (2002) also tested the construct validity of the RPT using 90 general psychology college students (50 women, 40 men, age range of 17-21 years, mean of 18.35 years) who completed a battery of personality scales including the RPT. These authors found that the expected subscale intercorrelations, gender differences and relationships with measures of attachment style, identity, relatedness, and affect emerged matching the original scale development findings of Bornstein and Languirand (2003).

The Worthington Autonomy Scale is a 40-item scale designed to measure autonomy across four domains: Family Loyalty autonomy, Value autonomy, Emotional autonomy, and Behavioral autonomy. Each domain is assessed with 10 statements 
(including 2 filler questions in 2 domains) that participants respond to on a 4-point Likert scale, indicating the extent to which they agree or disagree with the statement. This study only used the Emotional autonomy sub-scale (9 items), which refers to the desire to exert self-control, exercise emotional independence, and achieve interpersonal competence. Only the Emotional autonomy sub-scale was used because conceptualizations of psychological merger have been attributed to lack of emotional autonomy more than other types of autonomy (Peplau et al., 1978; Skoron \& Friedlander, 1998). This sub-scale uses items such as "I can be close to others and give them space at the same time." The authors report a Cronbach alpha value of .68 for Emotional autonomy sub-scale.

The Differentiation of Self Inventory is a 43-item multidimensional measure of differentiation that focuses on adult significant and family of origin relationships. This study used this inventory in order to gain a sense of participants' level of differentiation. Participants were asked to rate each item on a 1 to 6 scale from "not at all true of me" to "very true of me." The range of scores is 43 to 258 with higher scores indicating higher differentiation; most items are reverse coded.

The authors developed the DSI with a sample of 609 predominantly White, female, middle-class adults across three different studies. Principal components analysis and confirmatory factor analysis yielded four distinct dimensions of the single construct of differentiation of self: Emotional Reactivity, I Position, Emotional Cutoff and Fusion with Others. Some example items include: "I'm fairly self accepting" (I Position), "I wish that I weren't so emotional" (Emotional Reactivity), "I try to live up to my parents' expectations" (Fusion with others), "I have difficulty expressing my 
feelings to people I care for" (Emotionally Cutoff). Authors report moderate to high reliability calculations for each of the subscales: .88 (DSI), .88 (Emotional Reactivity), .85 (I-Position), .79 (Emotional Cutoff), and .70 (Fusion With Others).

Miranda and Storm's (1989) Sexual Orientation Disclosure Scale (SODS) was used to measure degree of outness, the extent to which participants have disclosed their sexual orientation to others. The 15 Likert-type items ask about different types of relationships in which lesbians may or may not be out to others (i.e. To other gay people, To your mother, To people involved with your housing). These items are rated on a seven-point scale with seven indicating the greatest degree of disclosure $(1=$ not "out" to $7=$ completely "out"). This scale ranges from scores of 15 to 105 with lower scores indicating less disclosure and higher scores indicating more disclosure of sexual coefficient of reproducibility of $\mathrm{r}(131)=.93$ and coefficient of scalability of $\mathrm{r}(131)=$ .67. The authors did not report validity information.

The Personal Assessment of Intimacy in Relationships (PAIR) Inventory was designed to conceptually define the multidimensional process of intimacy which Schaefer and Olson (1981) determined is comprised of two distinct dimensions: process and experience. The PAIR is both a theoretically and empirically driven scale of 27 items that measures the degree of desired and actual intimacy in five areas: Emotional Intimacy- the ability to feel close to someone, Social Intimacy- the ability to share mutual friends and similarities in social networks, Sexual Intimacy- the ability to share general affection and/or sexual activities, Intellectual Intimacy- the experience of share ideas, and Recreational Intimacy-shared interest in hobbies or joint participation in 
sport. The total range of scores is 0-96. This study only used the Emotional Intimacy sub-scale as the concentration of this exploration is on emotional closeness and posits that healthy emotional reliance is something conceptually different than emotional intimacy.

Schafer and Olson (1981) reported adequate convergent validity, discriminate validity, and slit-half reliability. The internal reliability of the PAIR is $\quad .70$ and that of the subscales is as follows: emotional $\quad .75$; social $\quad .71$; sexual $\quad .70$; intellectual $\quad$; and recreational . Sample items include: (Emotional) "My partner listens to me when I need someone to talk to," (Social) "We enjoy spending time with other couples." This investigation will only use the emotional intimacy subscale. It should be noted that this scale was intended for heterosexual couples, and to date, is not known to be used with lesbian couples before.

Colwell's (1988) Merger/ Disengagement Scale (MDS) was used to compare the healthy emotional reliance items to the merger items and provide discriminate validity. As such, this study only used Colwell's final Merging subscale of 13 items and not the Disengagement subscale. The MDS was originally developed to measure the dimensions of merging and disengagement that an individual perceives within her or his current relationship. Colwell used a sample of 26 lesbian couples, 21 gay male couples and 28 heterosexual couples in the Denver/ Boulder, Colorado area to validate her scale. Her results contradicted gender socialization expectations in that gay men were the most merged followed by lesbians and heterosexual couples. The scale was originally developed using a sample of 185 undergraduates in 1985, at which time, Colwell used a four-step process to analyze the scale and revise accordingly. As a result, she calculated 
Cronbach's alpha for her two subscales, Merger and Disengagement

\section{Demographics}

Results

Demographic data was summarized using descriptive statistics. The mean age of participants was 40.09 years $(\mathrm{sd}=11.395)$; the average length of participants' current relationship was 68.89 months ( $\mathrm{sd}=62.96$ ); 76.1 percent of participants cohabitated with their female partner. Among those who cohabitated, the mean length of time of cohabitation was 67.17 months $(\mathrm{sd}=65.60)$; and 20.9 percent of participants are parents (see Table 1). Two participants identified themselves as a gender other than female, one transgender and the other male.

Participants were asked to identify their sexual orientation both privately and publicly. It was the participants' decision how to define sexual orientation: in behavioral terms, emotions or any other variation of the term. Multiple answers were allowed, thus the total number of each sexual orientation identification category may total more than the number of participants: 226 (61.4 percent) of participants identified themselves privately as Lesbian, 44 (11.9 percent) as Bisexual; 32 (8.6 percent) as Gay, 27 (7.3 percent) as Queer, 17 (4.6 percent) as No Label, 15 (4 percent) as Dyke, 1 (.3 percent) as Heterosexual, and 1 (.3 percent) as Straight. The percentages were very similar for how participants identified publicly suggesting that most participants were "out": 226 (61.4 percent) of participants identified as Lesbian, 44 (11.9 percent) as Gay; 36 (9.7 percent) as No Label; 23 (6.2 percent) as Bisexual; 18 (6.8 percent) as Queer, 7 (1.9 percent) as Dyke, 6 (1.3 percent) as Heterosexual, and 5 (1.3 percent) as Straight 
(see Table 2). The length of time that participants had realized that they were attracted to women was 18.14 years $(s d=10.92)$.

This sample was mostly White, educated and reported higher incomes in general. In terms of ethnicity, 89.9 percent of participants were White, 2.4 percent Hispanic, 1.9 percent African American, 1.6 percent Native American, 1.4 Asian/ Pacific Islander and 2.7 percent of participants identified their ethnicity as other (see Table 3). Most participants were college educated, 30.4 percent held a Bachelor's degree another 40.5 percent held advanced or graduate degrees such as a master's or doctorate degree while 27.9 percent of participants had had post high school education and 1.1 percent of participants held a GED (see Table 3). Household income varied greatly most likely due to the range in age and the likely number of students. The mean yearly household income for this sample was $\$ 83,229.12(\mathrm{sd}=\$ 53,515.72)$ with a range of $\$ 424,700$ (see Table 1). Participants were recruited from every region of the United States: New England (47.3 percent), the Westcoast (26.1 percent), the MidAtlantic (7.3 percent), the Deep South ( 7.1 percent), the Midwest (5.7 percent), and Pacific Northwest (3.8 percent) (see Table 3).

\section{Scale development}

In order to develop a psychometrically sound scale to measure healthy emotional dependency in female couples, a pool of 50 items (see Appendix A) was subjected to principal components analysis (PCA) using SPSS. Principal components extraction was used to estimate number of components, presence of outliers, and factorability of the correlation matrices. With an alpha $=.05$ cutoff level, no item produced scores that were significantly different from the other items. 
Prior to performing PCA, the suitability of data for factor analysis was assessed. Inspection of the item correlation matrix revealed the presence of many coefficients of .30 and above which suggests that this data set was appropriate to subject to principal components analysis. As suggested by Tabachnick and Fidell (1996), with 50 items to be factors analyzed, a sample should have 5 cases per item, thus a sample of 250 is required. At 336, this sample meets these criteria. However, note that the entire sample of 336 was split in half in order to perform confirmatory analyses. Thus, Group 1 was made up of 141 cases and Group 2 used for confirmatory analyses consisted of 164 cases. Although this is less than 5 cases per item, many authors suggest that if items are expected to be highly correlated then less than 5 cases per item is adequate to submit to principal components analysis (Redding, Maddock \& Rossi, 2006). The Kaiser-MeyerOklin value was .91, exceeding the recommended value of .60 (Kaiser, 1974) and the Barlett's Test of Sphericity (Bartlett, 1954) reached statistical significance $(p<.01)$, supporting the factorability of the correlation matrix.

Principal Components analysis with Varimax rotation and pairwise deletion was performed on Group 1 revealed the presence of 10 components with eigenvalues exceeding 1. Results of Cattell's scree plot of the component variances showed a substantial break after three components (see Figure 2). Additionally, Lautenschlager's (1989) tables of average eigenvalues of random correlation matrices assuming independence were consulted. By comparing these tables to the obtained eigenvalues it was found that the first five eigenvalues exceeded those of the random eigenvalue tables. This is one way to estimate the appropriate number of components to extract. Four PCAs were then conducted in order to evaluate four different component solutions 
(three, four, five and six components). To aid in the interpretation of these three components, Varimax rotation was performed again. In each of the analyses most of the same items loaded on the first three components. Therefore, for statistical reasons and conceptual understanding, the three component solution was selected.

The rotated three component solution (see Table 4) revealed strong loadings on each of the three components. The three component solution explained a total of 41 percent of the variance with Component 1 contributing 26 percent, Component 2 contributing 10 percent, and Component 3 contributing 5 percent. To interpret the components, two criteria were used as guidelines, one, items needed to load on a single component and, two, items needed to have a loading of at least .50. However, some items that were close to meeting these criteria were further considered in additional analyses due to their conceptual richness. The resulting solution consisted of 26 items: thirteen items loaded on Component 1, seven items loaded on Component 2, and six items loaded on Component 3. A total of seventeen items did not load on any one component and eleven items were identified as complex (i.e., loading on more than one component). Four of these complex items were kept for further analysis based on content richness. A PCA was conducted on the remaining 26 items which showed two complex items and two other unstable items which were deleted. The resulting 22 -item scale was again subjected to PCA and another two items were deleted based on similar content and weak loadings. It was decided that the three remaining complex items (items 16,26 , and 27) did not significantly affect the results and were safe to keep for confirmatory analysis. A confirmatory PCA on the twenty items using Group 2 showed two more weak items, one which failed to load on any one component (item 49) and 
another that loaded on a component different from the component it loaded on in Group 1. These two items were deleted resulting in a final scale of eighteen items that consistently loaded on their respective components for both groups and the full sample. Confirmatory analyses were conducted again for the 18 items on Group 2 (see Table 6) and for the full sample (see Table 7). The following components were established: Component 1, with 9 items, was termed Interdependency; Component 2, with 5 items, was termed Attachment; and Component 3 with 4 items was termed Negative Dependence (see Appendix B for final scale items). In order to calculate reliability statistics between components, three sub-scales composite scores were calculated in SPSS by adding together the respective items under each of the three components. Descriptive Statistics

All scores were normally distributed; subscale means ranged from 2.31 to 4.27 (full-scale $M=3.07, \mathrm{SD}=.40$; see Table 8 ). Preliminary analyses were performed on the full sample, Group 1, and Group 2 to ensure no violation of the assumptions of normality and linearity. The results of the Kolmogorov-Smirnov statistic were significant at the .01 level for each the full sample, Groups 1 and Group 2 suggesting that there is a violation of the assumption of normality. However, in larger samples this is not uncommon (Pallant, 2001). Additionally, the histogram distribution for the full sample as well as both groups appears to be reasonably normal. Normality is also supported by the Normal Q-Q Plots which plots the observed value for each score "against the expected value from the normal distribution. A reasonably straight line [which is shown for this sample] suggests a normal distribution" (Pallant, 2001, p. 59). Further, the Detrended Normal Q-Q Plots looks at the actual deviation of scores from 
the straight line and plots them. This does not show clustering of points and most are collected around the zero line which also suggests adequate normality. The HERS full scale shows slight skewness (-.701) and kurtosis (.558). A small number of outliers were found according to an outlier analysis, however the $5 \%$ trimmed mean value (78.15) was very similar to the untrimmed mean value (77.76) suggesting that the outlier cases could safely be kept for analysis. Most final items were within the expected range in terms of means and standard deviation values (see Table 9). Some items suggested a bias in participant endorsement. For example, HERS item number 4 shows a mean of 4.52 which indicated that this particular item is generally endorsed by participants since the ratings are out of a total of five. However, the standard deviation value of .725 suggests low variability for this particular item, thus this item and others with high means and low standard deviation values, have high endorsement. These types of items can bias a scale and thus, they should be re-written so as to not encourage people to endorse the item.

Subscale- full-scale correlations using the entire sample were high for Interdependency $(r=.766, \mathrm{p}<.01)$ and moderate for Negative Dependence $(r=-.680$ ( $\mathrm{p}<.01)$, and small for Attachment, $r=-.286(\mathrm{p}<.01)$. Inter-correlations among the three subscales were low: $r=.268(\mathrm{p}<.01)$ (Interdependence and Attachment), $r=$ $.416(\mathrm{p}<.01)$ (Interdependence and Negative Dependence), and $r=.119(\mathrm{p}<.05)$ (Attachment and Negative Dependence). Table 10 shows these correlations for the entire sample and by group.

Internal consistency estimates using Cronbach's alpha suggested high reliabilities for the HERS total scale and each of the three subscales. Analyses were 
undertaken for each of the HERS subscales (Interdependency, Attachment, and Negative Dependence). As shown by table 11, all components show good reliability in both halves

reliability analyses showed high reliability for all three subscales: Interdependency, .817; Attachment, .716; and Negative Dependence, .851.

Tests of Hypotheses

Hypothesis 1. Hypothesis one stated that the Healthy Emotional Reliance Scale will be comprised of four components: interdependence, emotional autonomy, differentiation; and satisfaction which constitute the experience of healthy emotional reliance in female couples. This hypothesis was partially supported. First, three components rather than four were identified. Further, once the content of the final items was considered, it made more sense to name the emerged constructs: Interdependency, as was originally conceptualized, Attachment, originally conceptualized as Emotional Autonomy, and Negative Dependence, originally conceptualized as Differentiation. While three components emerged, they were not correlated highly enough to statistically substantiate a hierarchical model in which the three components of Interdependence, Attachment and Negative Dependence all contributed to the single construct of Healthy Emotional Reliance. Thus, the results of these analyses show three separate constructs all with strong reliabilities. Therefore, this is a multi-dimensional scale. Items that were expected to load on a fourth component to capture the concept of relationship satisfaction were too highly correlated with other component items to stand alone as a separate component. 
Hypothesis 2. Hypothesis two stated that construct validity can be established for healthy emotional reliance by demonstrating positive correlations between certain HERS items and validated measures thought to relate to the expected emerged subscales: interdependence was thought to positively correlate with the Healthy Dependency subscale of the Relationship Profile Test, emotional autonomy was thought to positively correlate with the Emotional Autonomy subscale of the Worthington Autonomy Scale; and differentiation was thought to positively correlate with the $I$ Position subscale of the Differentiation of Self Inventory. Further, hypothesis 2 stated that discriminate validity could be established for healthy emotional reliance by demonstrating the lack of a significant relationship between the total HERS and the Emotional Intimacy subscale of The Personal Assessment of Intimacy in Relationships Inventory.

The above expected relationships or lack of a relationship between each of the three components extracted (Interdependency, Attachment, and Negative Dependence) or the total HERS and the respective subscales of previously validated measures originally expected to correlate with these subscales (Healthy Dependency subscale of the Relationship Profile Test, Emotional Autonomy subscale of the Worthington Autonomy Scale; and the I-Position subscale of the Differentiation of Self Inventory, and Emotional Intimacy of the Personal Assessment of Intimacy in Relationships Inventor) were investigated using Pearson product-moment correlation coefficients.

As hypothesized, bivariate correlation analyses showed a significant moderate (Cohen, 1988) positive correlation between Component 1 of the HERS (Interdependency) and the Healthy Dependency sub-scale of the Relationship Profile 
Test $(r=.313, \mathrm{p}<.01)$ indicating high levels of interdependency associated with high levels of healthy dependency. Due to the change in conceptualization of Component 2 of the HERS from Emotional Autonomy to Attachment, the weak significant correlation between this component and the Emotional Autonomy subscale of the Worthington Autonomy Scale $(r=.117, \mathrm{p}<.05)$ is not an appropriate comparison. Instead another validated adult attachment measure should be used to establish construct validity for this subscale. Component 3 (Negative Dependence) was significantly correlated with the I-Position subscale of the Differentiation of Self Inventory $(r=.215, \mathrm{p}<.01)$ and the Emotional Reactivity subscale $(r=.148, \mathrm{p}<.05)$. Again, however, due to the change in conceptualization of this component, these results cannot be taken at face value. An unhealthy dependency scale would need to be administered in order to address the comparison at hand. Since the RPT has a Destructive Overdependence subscale, this was submitted for analysis with the Negative Dependence subscale. The result indicates that Negative Dependence has a moderate positive relationship with Destructive Overdependence. Additionally, Negative Dependence had a modest negative relationship with Attachment $(r=-.119, \mathrm{p}<.01)$ suggesting that attachment is increased by the absence of negative dependency. Given these considerations, the above results weakly support construct validity for the Interdependency and Negative Dependency subscales, however, construct validity for the Attachment subscale is unknown due to a lack of appropriate comparison measure (see Table 12).

The full scale HERS score had a moderate significant negative relationship with the "what it is like now" part of the Emotional Intimacy subscale of the Personal Assessment of Intimacy in Relationships Inventory (PAIRnow) $(r=-.427, \mathrm{p}<.01)$. While 
this findings suggests that there exists a relatively strong relationship between Emotional Intimacy as measure by the Personal Assessment of Intimacy in Relationships Inventory and the full scale score of the HERS, this cannot be interpreted as such because there is not sufficient statistical evidence for a meaningful full scale score on the HERS since the subscales do not correlate highly enough to suggest a hierarchical relationship. The Interdependency subscale of the HERS showed a strong significant negative relationship with the "what it is like now" part of the Emotional Intimacy subscale of the PAIR $(r=-.508, \mathrm{p}<.01)$. This finding suggests a significantly strong relationship between emotional intimacy and Interdependency and, thus, does not support hypothesis 2 . However, it important to note that hypothesis 2 was ill-conceived since emotional intimacy and relationship satisfaction are inevitably expected to being highly positively correlated and hypothesis 4 predicted that relationship satisfaction would be positively correlated with the HERS which necessitates that the HERS be significantly correlated with Emotional Intimacy, the opposite of the originally stated hypothesis 2 . Additionally the Attachment subscale significantly positively correlated with the MDS $(r=.574, \mathrm{p}<.01)$. This indicates that there is a strong relationship between Merger as it is defined and measured by Cowell, and Attachment such that the more merged an individual the, the more attached they are as well.

Hypothesis 3. Hypothesis three states that a significant positive relationship between the degree of outness, as determined by the SODS, and healthy emotional reliance, as measured by the HERS, will exist for individual women currently part of a female couple. This hypothesis was supported by the significant correlation between the SODS and HERS $(r=.294, \mathrm{p}<.01)$; however, a full scale HERS score cannot be 
interpreted. Thus, the significant correlation $(r=.224, \mathrm{p}<.01)$ between the Interdependency subscale and the SODS was interpreted instead (see Table 12).

Hypothesis 4. Hypothesis four stated that there exists a significant positive correlation between the level of healthy emotional reliance, as measured by the total score of the HERS, and degree of satisfaction with a current relationship, as measured by relationship satisfaction items on the HERS, for individual women currently part of a female couple. Although the relationship satisfaction items did not load on a separate component of the HERS, as a separate scale, these items (HERS original items \# 11, 17, 18 , valid full scale score for the HERS did not emerge, conclusions about the relationship between the full sale score on the HERS and the construct of relationship satisfaction cannot be drawn. Instead, the correlation between the relationship satisfaction items as a composite score and the individual HERS subscales was interpreted. Accordingly, relationship satisfaction showed a strong, significant positive correlation with the Interdependency $(r=.793 ; \mathrm{p}<.01)$ subscale and a strong negative correlation with the Negative Dependence $(r=-.549 ; \mathrm{p}<.01)$ subscale of the HERS. Relationship satisfaction and Attachment showed a weak positive correlation $(r=.145, \mathrm{p}<.01)$. for the full sample. These results suggest that Interdependency and, to a limited degree, Attachment contribute to relationship satisfaction; however negative dependency does not positively relate to relationship satisfaction (see Table 13).

Given the very strong correlation between relationship satisfaction and Interdependency, it is important to consider the possibility of collinearity between these two constructs. As such, the relationship between relationship satisfaction and 
Interdependency is so strong that the two may in fact be measuring too similar of a dimension. In other words, the items of the Interdependency subscale written to measure interdependency could actually be measuring a combination between interdependency and relationship satisfaction. If this is the case, then the interpretation of the correlation between the Interdependency subscale and the relationship satisfaction items cannot be disentangled from one another enough to show their relationship as separate constructs. Thus, the association between interdependency and relationship satisfaction may not be a reliable one. This consideration needs to also be applied to hypothesis 3 in which "outness" may be associated with a combination between relationship satisfaction and Interdependency rather than Interdependency alone. It was expected that "outness" would be associated with relationship satisfaction. Correlation analyses were also performed on the relationship satisfaction items with the PAIRnow, RPThd and SODS in order to explore the relationship between relationship satisfaction and intimacy and healthy dependency, and the relationship between degree of outness and relationship satisfaction. As presented in Table 13, relationship satisfaction is moderately positively related to healthy dependency $(r=$ $.317, \mathrm{p}<.01)$ as measured by the Healthy Dependency subscale of the RPT and degree of outness $(r=.383, \mathrm{p}<.01)$ as measured by the SODS. Note that the relationship between outness and interdependency $(r=.224, \mathrm{p}<.01)$ was slightly weaker than the relationship between outness and relationship satisfaction which further supports the idea that the Interdependency subscale and relationship satisfaction items are similar but not identical. A confusing finding was that relationship satisfaction was negatively correlated with emotional intimacy $(r=-.449, \mathrm{p}<.01)$ as measured by the PAIR. It is 
unclear why this result surfaced as a negative relationship rather than a positive one based on the expectation that relationship satisfaction should be positively correlated with emotional intimacy.

\section{Discussion}

The main aim of this research was to construct a reliable and valid self-report measure of healthy emotional reliance in female couples using a construct approach to test development. This aim was partially realized in this exploration. An 18 item scale entitled the Healthy Emotional Reliance Scale (HERS) was constructed through Principal components analysis to measure the healthy portions of merger in female couples. Three independent components emerged: Interdependency, Attachment and Negative Dependence. However, a full scale score for the combination of these subscales did not emerge as indicated by low inter-subscale correlations. As such, the resulting scale is a multi-dimensional one in which several separate constructs are part of one measure rather than a hierarchical model in which components are able to combine in such a way as to create a single construct.

The model of Healthy Emotional Reliance, as a whole, postulated that healthy emotional reliance in female couples is positive, adaptive, healthy, and instrumental to the personal growth of the female individual and the female couple together. With regard to interdependency, in order to have healthy emotional connections, one must be able to open themselves up to emotional vulnerability, yet maintain some emotional distance in order to differentiate between themselves and the other. Items that measure this construct have to do with individuals being comfortable depending on their partner and having their partner depend on them. This construct assumes that partners are able 
to emotionally connect in a satisfying yet not burdensome way. Some example items are: "I like that my partner and I are comfortable depending on one another;" and "I know that I can rely on my partner to meet many of my personal needs."

The Attachment subscale is meant to measure emotional closeness and connection between partners. Originally this subscale was conceptualized as Emotional Autonomy. However, once the items emerged, Attachment better described the content areas that these items capture. These items have to do with the degree of attachment that an individual has for their partner. Items ask participants about ways in which their partner satisfies specific emotional needs. Ideally the items written for this component named attachment teases out over-emotional dependency from emotional selfsustainability. Healthy Attachment between partners is conceptualized as the ability to sustain emotional stability of one's own and be able to recognize one's emotional undertakings as a separate process from that of an individual's partner. Two example items from this subscale are: "I seem to never want to be away from my partner;" and "I do not need my partner to be emotionally stable."

The Negative Dependence subscale is used to describe the type of dependency between partners which is overbearing and dissatisfactory. These items are written in a way as to assess degree of unhealthy or over-dependency between a couple. This subscale was originally conceptualized as Differentiation; however, again as a result of the content that arose from the items distinguished by statistical analyses for this component, the construct was reconsidered and termed Negative Dependence instead. Under this new conceptualization, this subscale best aligns with Bornstein and Languirand's (2003) concept of Destructive Overdependence. Some example item are: 
"I wish that my partner and I were more independent." and "Sometimes I feel resentful of the time my partner demands from me."

Confirmatory principal components analysis demonstrates support for the HERS subscales: Interdependency, Attachment, and Negative Dependence as identifiable, empirically distinct dimensions theoretically related to healthy emotional reliance. Cronbach alpha reliability analyses of the HERS subscales supported strong internal consistency (Interdependency, $=.878 ;$ Attachment, $=.753 ;$ Negative Dependence, $=.806)$.

The three subscales correlated with each other in interesting ways. Interdependency was moderately positively related to Attachment $(r=.268, \mathrm{p}<.01)$ suggesting that as attachment increases so does interdependency. The modest negative correlation between Attachment and Negative Dependence $(r=-.119, \mathrm{p}<.01)$ indicates that Attachment is inversely related to negative dependence such that an unhealthy or over-dependency does not facilitate attachment. Thus, Attachment is somewhat related to the lack of unhealthy dependency. This is an interesting finding although expected given the psychological literature about the damaging effects of over-dependency as is somewhat illustrated by inflexible and unhealthy portions of merger. Further the fairly strong negative correlation between Interdependency and Negative Dependence $(r=-$ $.416, \mathrm{p}<.01)$ strongly suggests that it is a level of dependency in the relationship that the respondent experiences as too much and is the lack of this negative dependency that is strongly associated with interdependency.

This is further supported by the very strong positive relationship found between Interdependency and relationship satisfaction $(r=.793, \mathrm{p}<.01)$. Thus, the lack of 
negative dependence is positively associated with relationship satisfaction. Conversely, Negative Dependence was strongly inversely associated with relationship satisfaction ( $r$ $=-.549, \mathrm{p}<.01$ ), while Attachment was significantly positively related to relationship satisfaction $(r=.145, \mathrm{p}<.01)$. This explicates that relationship satisfaction for this population of women is related to a lack of negative dependency and the existence of attachment. However, the positive correlation between the Attachment subscale and relationship satisfaction is fairly small. This could be resulting from the fact that the items were written with a different construct in mind, emotional autonomy, and first conceptualized as being reverse coded.

The Interdependency subscale showed a strong positive correlation with the Healthy Dependency subscale $(r=.313 ; \mathrm{p}>.01)$ showing that the Interdependency subscale is measuring something similar to Bornstein and Languirand's (2003) concept of Healthy Dependency. It was expected that this correlation would be stronger given the overlap in conceptual definitions, however, the difference in focus of the Interdependency subscale and the Healthy Dependency subscale may account for the resulting weaker correlation. The HERS items are all directed towards the individual in a relationship, however, the Relationship Profile Test (RPT) items are written for the individual regardless of their relationship status. Therefore, the resulting difference in focus may have changed the interpretation of the items, resulting in different scores, thus creating a lower correlation between the two measures.

Due to the change in conceptualization of Component 2, Attachment (originally Lack of Emotional Autonomy) and Component 3, Negative Dependence (originally Lack of Differentiation), it is difficult to assert construct validity claims. However, 
Negative Dependence and the Destructive Overdependence subscale of the Relationship Profile Test showed a significant moderate positive correlation $(r=.370 ; \mathrm{p}>.01)$ indicating that the Negative Dependence subscale is indeed measuring something like destructive overdependence which is defined by Bornstein and Languirand (2003) as maladaptive and inflexible dependency versus healthy dependency which is characterized by flexible, adaptive, help-and support- seeking. Interestingly, although somewhat expected, the Attachment subscale strongly positively correlated with Colwell's (1988) Merger subscale of the Merger/ Disengagement Scale (MDS; Cowell, 1988) $(r=.574 ; \mathrm{p}>.01)$. This strongly suggests that the Attachment subscale is measuring something similar to the Merger that Cowell (1988) conceptualized as an individual who has "a sense of overdependence on and clinginess with one's partner, tendency to feel abandoned, depressed, alone, and alienated when not with one's partner, some reluctance to assert one's own needs if it might jeopardize one's relationship" (p. 84-85) among other characteristics.

Even more interestingly, Cowell's Merger subscale (1988) strongly positively correlated with Bornstein and Languirand's (2003) Destructive Overdependence ( $r=$ $.446 ; \mathrm{p}>.01)$. This indicates that Merger, as defined by Cowell (1988), is comprised of not only attachment, but destructive overdependence as well. It seems that attachment speaks to the dynamics of the relationship dyad and dependence speaks to the emotional stability of the individual within the dyad. Of course, not all of the literature around dependency is focused on abnormal patterns. Hirschfeld, Klerman, Gough, Barrett, Korchin, and Chodoff (1977) describe interpersonal dependence found in normal adult personality structures as 
a complex of thoughts, beliefs, feelings, and behaviors which revolve around the need to associate closely with, interact with, and rely upon valued other people. The thoughts concern views of self and one's relationships with others. The beliefs pertain to the value one places on friendship, intimacy, interdependency, etc. The feelings include both positive and negative emotions. The behaviors seek to maintain interpersonal closeness, for example, by being 'pleasant,' giving or requesting advice, or helping others ( $p$. $610)$.

This definition speaks to the multiple components of interpersonal dependence as a construct that affects many parts of the individual: emotions, behaviors, and thoughts. As such it seems that an imbalance of these components results in destructive, maladaptive, inflexible and/ or unhealthy dependency.

It had been hypothesized that healthy emotional reliance would be differentiated from emotional intimacy. Originally, this investigation identified healthy emotional reliance as "something different, something more than intimacy... an actual pattern of relating with closeness and interdependency that is healthy, adaptive, and conducive to emotional autonomy and differentiation." However, this does not makes sense given that it was also hypothesized that healthy emotional reliance would also be strongly positively related to relationship satisfaction and relationship satisfaction is theoretically expected to be highly correlated with emotional intimacy especially for women.

Regarding the relationship satisfaction hypothesis results, the very strong positive correlation $(r=.793, \mathrm{p}<.01)$ between the relationship satisfaction items and the Interdependency scale could indicate that the items on these two constructs are very similar and possibly too similar to be able to interpret the correlation between them. This means that the two constructs could be too highly correlated to be able to distinguish one from the other in order to reliably draw conclusions about the 
relationship between them. Because the relationship satisfaction items came from the same 50 item pool as the Interdependency subscale items and because the relationship items originally loaded on the first component, later identified as Interdependency, it is not surprising that the two sets of items would be very similar and show a high correlation. For example item number 7 states, "My partner and I support each other." This statement may speak more to relationship satisfaction than it does interdependency as most people would consider the support of their partner a positive aspect to their relationship and one that contributes to their relationship satisfaction. However, other items such as item number 27 speak more clearly to interdependency, "I like that my partner and I are comfortable depending on one another."

This is not to say that the Interdependency subscale items and the relationship satisfaction items are identical, but rather that they are highly similar. This finding is supported by the difference in correlations between other measures and the Interdependency subscale compared to the relationship satisfaction composite score. For example outness, as measured by the SODS, is correlated with the Interdependency subscale $(r=.224, \mathrm{p}<.01)$ slightly lower than it is correlated with the composite score of the relationship satisfaction items $((r=.383, \mathrm{p}<.01)$. Therefore, more outness is correlated with a higher degree of interdependency and to a greater degree, more relationship satisfaction. Given these findings, future explorations would benefit from a separate relationship satisfaction measure. Further, this would be most beneficial if the measure was written specifically for female couples and was orientated towards the couple as opposed to the individual. 
According to the results of this investigation, merger seems most similar to Negative Dependence, while healthy emotional reliance seems most similar to Interdependency. Since all three subscales showed good internal reliability, each subscale could be used separately to for clinical assessment of female couple purposes. The Negative Dependence sub-scale could be used to assess merger in female couples whereas the Interdependence sub-scale could be used to assess healthy emotional reliance in female couples. As suggested earlier, these results can be useful in helping clinicians to re-conceptualize dependency issues in their female clients and especially female coupled clients.

Taken all together, this investigation showed that Attachment and Autonomy are not polar opposites on a single dimension, but rather that these are individual dimensions and that it is quite possible to be strongly orientated towards both ideals simultaneously. As indicated by previous studies and an abundance of past theory, women in particular have been socialized to value connection more so than separation. However, as suggested by the results of this study, female couples also have the ability to maintain a level of interdependency that does not result in co-dependence and does not interfere with individual satisfaction with the relationship. Indeed, two women are capable of relating to one another with intimacy and closeness while maintaining boundaries and individual functioning. This is the experience of healthy emotional reliance if you will.

\section{Limitations of the Study and Future Directions}

There are several obvious limitations to this study. The most obvious is the lack of ethnic diversity with an 89 percent White sample. Further, most participants were 
educated and earning good incomes. Therefore, the conclusions drawn from this study cannot be readily applied to all women in relationships with other women, but rather generalizability is limited to White, educated, high income earners. The methodology of this study also required participants to be computer and internet savvy. Consequently, the population surveyed was also limited in that they were a sub-set of women who either owned or had access to a computer and the internet as well as the desire and know how to complete an online survey. Additionally, participants in this study may have more interested in, be more comfortable with and/ or more trusting of psychological research and psychologists.

Due to the hidden identities of many women with whom this study is concerned, many authors (Patterson, 1995; Peplau, Cochran \& Padesky, 1978) have exclaimed that there is no such thing as a representative sample for such a hidden population. Thus, while it is difficult to obtain a more diverse sample, this study did achieve at least regional diversity across the nation. Nevertheless, diversity of the sample could be expanded more by utilizing lesbian, gay, bisexual, trangender, queer (LGBTQ) community centers of major cities across the U.S. Additionally, gay friendly churches and church groups, LGBTQ support groups, LGBTQ discussion, as well as feminists centers could be surveyed. Of course, these places would also house mostly "out" individuals. One advantage of an online study is that it does not require people to be publicly out; however they do need to be at least somewhat privately out to themselves. Participants would also be obtained from sexuality conferences and conventions. In the above environments, the researcher could provide laptops for participants to use and thus, eliminate the need for data entry and save considerable amounts of time. It would 
be most beneficial if these methods were used in addition to the online survey and snowball methodology.

Another important consideration is the presence of highly endorsed items which can pose a threat to accurately distinguishing between dimensions. For instance, some items of the HERS such as item number 4, "I feel safe and secure within my relationship with my partner." is likely to be endorsed by participants who either are satisfied with their relationship speaking to the issue detailed above, or have a desire to appear this way both to themselves and the test interpreter. Thus, this type of question which elicited a high response rate (mean $=4.52$ out of a possible 5 ) based on influences not necessarily targeted by the question. In this case, the participant is answering according to relationship satisfaction or social desirability rather than as representation of their level of interdependency as is intended by this subscale. Given this, items with these characteristics should be re-written as to not encourage participants to endorse the statement and better distinguish between constructs.

Regarding the chosen measures used to establish construct validity, it seems that the construct of emotional autonomy was not as appropriate to the dimension of dependency as is attachment. Therefore, the Emotional Autonomy subscale of the Worthington Autonomy Scale (WAS) is not appropriate for establishing construct validity. Further, the WAS has an individual focus as opposed to the partner focused used by the HERS. This same issue applies to the Differentiation of Self Inventory (DSI) which is also meant to assess individual functioning rather than the function of an individual within a dyad as the HERS does. Thus, future validation studies need to choose better equipped measures both in style and appropriateness of construct 
measured. Future studies should use a valid and reliable Attachment measure directed towards the individual in a couple and an unhealthy or overdependence measure again focused on the individual within a couple. Using two subscales from the same measure such as Healthy Dependency and Destructive Overdependence from the Relationship Profile Test (RPT) could statistically be problematic. Thus, separate measures for these two concepts would relieve potential statistical complications.

It is also important to note that the term healthy is being used to describe adaptive, functional and satisfying components of relational dynamics. However, participants were not given any assessment of emotional well-being or questionnaire of healthy behaviors. Thus, this study is severely limited in its ability to state explicitly that the concepts being put forward necessarily indicate healthy functioning. Rather, the concept of healthy is essentially being assessed by the items of relationship satisfaction. Thus, for this research, healthy is defined as one's own perception of their degree of relationship satisfaction. Additionally, it is important to note that the relationship items were constructed for the purposes of this study and were not previously validated or shown to be reliable. These items did, however, show strong and operationalized definition of emotional health. Additionally, a valid and reliable assessment of emotional well-being which fits this definition should be used to measure emotional health in the sample. Further, emotional health may be better assessed using behavioral measures such as the amount of time a couple spends together, the number of activities a couple shares, sexual fidelity, etc. Such behavioral measures may be 
better suited to quantify the closeness of a relationship rather than other subjective statements about degrees of emotion.

\section{Conclusion}

Human connection is a vital part of survival; we are social beings meant to depend on each other, help each other and trust each other as a way to become emotionally connected. As Lichtenberg (1991) explains that intimacy between partners is created by the balancing of self-assertion and mergence; however in our society selfassertion is perceived as the epitome of individuality, thus in order to affirm oneself as unique, independent and autonomous, we are required to set ourselves apart from others. Rather, as this research implies, "individuality is also a function of a person's method of merging with others. It requires that we open ourselves to embeddedness in a social unit while we close the circle of our separateness" (p. 32). The psychological literature around dependency is rich. Usually dependency holds a negative connotation that conjures experiences of overdependence and co-dependence. Bornstein and Languirand (2003) have helped to depathologize dependency with their assertion of Healthy Dependency. It is hoped that this investigation has furthered this cause to highlight the importance of connection in a society that values separation.

The mutual reliance of two people in relation with the simultaneous ability to differentiate from one another is a gift and interpersonal treasure that few find the balance to create within their relationships. Socialization and other psychological models have taught us to disconnect such that we are entrenched in the idea that to be an individual is to be an island, yet we find that we need others to build community, a sense of belonging, a sense of life meaning... simply we need to learn to reconnect. We 
need to learn to be comfortable needing others, seeking the help of others as well as lending our support.

This data collected as part of this investigation is rich with possibilities. This researcher plans to continue to investigate the patterns and questions that surface through this data. Additionally a second validation of the HERS is planned for future research. It is important that the field have a psychometrically sound measure to help further research on female couples as well as a diagnostic tool for clinicians serving female couples in therapy. Many other parts of this issue can be explored in the future. For instance, gender differences on the HERS could be investigated as well as differences between women who identify as more masculine and those who identify as more feminine and in a relationship with another woman. Further, qualitative data was collected as part of this research. The researcher plans to analyze this data around what is means to have healthy emotional reliance. It is expected that these further sources of information will be rich in content and further add to the growing field of LGB studies and to relationship studies of all types of romantic dyads. 
Table 1:

Demographic Statistics for Participants

Demographic $\quad \underline{N}$ Minimum Maximum Mean $\underline{\text { Std. }}$

Deviation

$\begin{array}{cccccc}\text { Age } & 368 & 18 & 81 & 40.09 & 11.39 \\ \begin{array}{c}\text { Cohabitation time (months) } \\ \text { Relationship time (months) }\end{array} & 276 & 1 & 363 & 67.17 & 65.60 \\ \begin{array}{c}\text { Length of Cohabitation } \\ \text { (months) }\end{array} & 276 & 1 & 396 & 68.89 & 62.96 \\ \begin{array}{c}\text { Length of time "out" (years) } \\ \text { Household Yearly Income }\end{array} & 325 & 0 & 75 & 18.14 & 10.92 \\ & 340 & \$ 300 & \$ 425,000 & \$ 83,229.12 & \$ 53,515.72\end{array}$

Table 2:

Private and Public Sexual Orientation of Participants

Private Sexual Orientation Frequency Percent

\begin{tabular}{lcc}
\hline Lesbian & 226 & 61.4 \\
Bisexual & 44 & 11.9 \\
Gay & 32 & 8.6 \\
Queer & 27 & 7.3 \\
No Label & 17 & 4.6 \\
Dyke & 15 & 4.0 \\
Heterosexual & 1 & .3 \\
Straight & 1 & .3 \\
Public Sexual Orientation & & \\
Lesbian & 226 & 61.4 \\
Gay & 44 & 11.9 \\
No Label & 36 & 9.7 \\
Bisexual & 23 & 6.2 \\
Queer & 18 & 6.8 \\
Dyke & 7 & 1.9 \\
Heterosexual & 6 & 1.4 \\
Straight & 5 & 1.3 \\
\hline
\end{tabular}


Table 3:

Ethnicity, Education Level, Geographical Region of Participants

Variable $\quad \underline{\text { Frequency }}$ Percent

\begin{tabular}{lcc}
\hline Ethnicity & & \\
White & 331 & 89.9 \\
Hispanic & 9 & 2.4 \\
Black/ African American & 7 & 1.9 \\
Asian/ Pacific Islander & 5 & 1.4 \\
Native American & 6 & 1.6 \\
Other & 10 & 2.7
\end{tabular}

Degree Earned

GED

High School Diploma

Technical Degree

Some College

Associates Degree

Bachelor's Degree

Advanced Certification

Master's Degree

Doctorate (Ph.D., M.D., J.D.)
4

$13 \quad 3.5$

$4 \quad 1.1$

$59 \quad 16.0$

$27 \quad 7.3$

$112 \quad 30.4$

$18 \quad 4.9$

$102 \quad 27.7$

$29 \quad 7.9$

\section{$\underline{\text { Region }}$}

New England

174

47.3

Mid-Atlantic

27

7.3

Deep South

26

7.1

Midwest

21

5.7

Southwest

$10 \quad 2.7$

Westcoast

96

26.1

Pacific Northwest

$\begin{array}{ll}14 & 3.8\end{array}$


Table 4:

Rotated Component Matrix

Scale Item Component

\begin{tabular}{|c|c|c|c|}
\hline & 1 & 2 & 3 \\
\hline HERS19 & .767 & .264 & .302 \\
\hline HERS3 & .760 & .165 & .060 \\
\hline HERS7 & .732 & .135 & .296 \\
\hline HERS13 & .731 & .107 & .122 \\
\hline HERS26 & .696 & .183 & .319 \\
\hline HERS4 & .686 & .177 & .273 \\
\hline HERS37 & .680 & .083 & -.147 \\
\hline HERS1 8 & .666 & .122 & .480 \\
\hline HERS46 & .630 & .190 & .191 \\
\hline HERS 10 & .629 & .227 & .095 \\
\hline HERS 17 & .620 & .240 & .474 \\
\hline HERS36 & .607 & .410 & .115 \\
\hline HERS48 & .588 & .024 & .102 \\
\hline HERS20 & .571 & .046 & .244 \\
\hline HERS45 & .553 & .180 & .412 \\
\hline HERS38 & .552 & .368 & .048 \\
\hline HERS27 & .549 & .330 & .083 \\
\hline HERS49 & .536 & -.065 & .227 \\
\hline HERS1 & .528 & .098 & .346 \\
\hline HERS6 & .498 & .290 & -.087 \\
\hline HERSII & .444 & -.153 & .331 \\
\hline HERS28 & .443 & -.317 & .310 \\
\hline HERS33 & .440 & -.140 & -.081 \\
\hline HERS22 & .417 & -.143 & .408 \\
\hline HERS40 & -.375 & .206 & -.240 \\
\hline HERS34 & .343 & .304 & .174 \\
\hline HERS15 & .075 & -.733 & -.103 \\
\hline HERS43 & .145 & -.703 & -.013 \\
\hline HERS41 & .146 & -.695 & .032 \\
\hline HERS5 & -.109 & --.621 & .183 \\
\hline HERS50 & .226 & -.611 & .022 \\
\hline HERS42 & .057 & -.603 & -.073 \\
\hline HERS9R & -.049 & -.566 & .033 \\
\hline HERS2 & .330 & -.548 & .057 \\
\hline HERS8R & -.392 & -.497 & -.135 \\
\hline HERS32 & .011 & -.485 & -.197 \\
\hline HERS44R & .283 & -.405 & .027 \\
\hline HERS35R & -.012 & -.400 & .366 \\
\hline HERS25 & .159 & .320 & .053 \\
\hline HERS24 & -.036 & .289 & -.121 \\
\hline HERS29 & .206 & .260 & -.136 \\
\hline HERS30 & .142 & .229 & .165 \\
\hline HERS21 & .254 & .266 & -.712 \\
\hline HERS14 & .019 & .042 & -.697 \\
\hline HERS 31 & .195 & .243 & -.690 \\
\hline HERS 23 & -.075 & -.247 & -.677 \\
\hline HERS 16 & .318 & -.111 & -.666 \\
\hline HERS47 & .223 & .154 & -.586 \\
\hline HERS 12 & .117 & -.078 & .198 \\
\hline HERS39 & -.047 & .038 & -.154 \\
\hline
\end{tabular}


Table 5:

Rotated Component Matrix-Group 1 (18 Items)

\begin{tabular}{|c|c|c|c|}
\hline \multirow{2}{*}{ Scale Item } & \multicolumn{3}{|c|}{ Component } \\
\hline & 1 & & 3 \\
\hline HERS3 & .798 & .119 & -.094 \\
\hline HERS13 & .768 & .103 & -.020 \\
\hline HERS7 & .762 & .285 & -.090 \\
\hline HERS4 & .748 & .291 & -.122 \\
\hline HERS26 & .711 & .343 & -.098 \\
\hline HERS10 & .688 & .092 & -.227 \\
\hline HERS37 & .685 & -.022 & -.009 \\
\hline HERS48 & .622 & .020 & .025 \\
\hline HERS 27 & .578 & .139 & -.304 \\
\hline HERS2 1 & .240 & -.831 & -.138 \\
\hline HERS31 & .178 & -.797 & -.119 \\
\hline HERS14 & .019 & -.743 & .065 \\
\hline HERS47 & .227 & -.720 & .021 \\
\hline HERS5 & -.109 & .085 & -.721 \\
\hline HERS43 & -.149 & -.099 & -.708 \\
\hline HERS42 & .005 & -.019 & -.696 \\
\hline HERS15 & -.124 & -.053 & -.682 \\
\hline HERS9R & -.041 & -.047 & -.648 \\
\hline
\end{tabular}

Table 6:

Rotated Component Matrix-Group 2 (18 Items)

\begin{tabular}{cccc} 
Scale Item & \multicolumn{3}{c}{ Component } \\
& 1 & 2 & 3 \\
\hline & & & \\
\hline HERS4 & $\mathbf{. 8 6 4}$ & .008 & .131 \\
HERS48 & $\mathbf{. 7 5 4}$ & .116 & .051 \\
HERS13 & $\mathbf{. 7 3 1}$ & -.129 & .184 \\
HERS26 & $\mathbf{. 7 0 0}$ & -.012 & .327 \\
HERS3 & $\mathbf{. 6 8 1}$ & -.176 & .152 \\
HERS7 & $\mathbf{. 6 7 1}$ & .017 & .232 \\
HERS37 & $\mathbf{. 6 1 5}$ & -.084 & .050 \\
HERS10 & $\mathbf{. 5 9 0}$ & -.280 & .063 \\
HERS27 & $\mathbf{. 5 7 0}$ & -.321 & .149 \\
HERS42 & .071 & $\mathbf{- . 7 5 8}$ & -.036 \\
HERS43 & -.188 & -.725 & -.154 \\
HERS5 & -.163 & -.701 & .090 \\
HERS15 & -.046 &.$- \mathbf{6 7 7}$ & -.089 \\
HERS9R & -.067 & $\mathbf{- . 6 6 9}$ & .001 \\
HERS31 & .152 & -.041 & $\mathbf{- . 8 5 9}$ \\
HERS21 & .196 & -.023 & $\mathbf{- . 8 5 7}$ \\
HERS14 & .111 & -.004 & $\mathbf{- . 7 3 3}$ \\
HERS47 & .277 & -.112 & $\mathbf{- . 5 7 6}$ \\
\hline
\end{tabular}


Table 7:

Rotated Component Matrix- Full Sample (18 Items)

Scale Item Component $1 \quad 2 \quad 3$

\begin{tabular}{cccc}
\hline HERS4 & $\mathbf{. 8 0 7}$ & .207 & -.049 \\
HERS13 & $\mathbf{. 7 4 5}$ & .147 & -.078 \\
HERS3 & $\mathbf{. 7 4 4}$ & .131 & -.138 \\
HERS7 & $\mathbf{. 7 1 9}$ & .256 & -.032 \\
HERS26 & $\mathbf{. 7 0 2}$ & .340 & -.050 \\
HERS48 & $\mathbf{. 6 8 3}$ & .045 & .077 \\
HERS37 & $\mathbf{. 6 5 3}$ & .007 & -.045 \\
HERS10 & $\mathbf{. 6 4 6}$ & .070 & -.248 \\
HERS27 & $\mathbf{. 5 7 7}$ & .139 & -.307 \\
HERS21 & .223 & $\mathbf{- . 8 4 3}$ & -.079 \\
HERS31 & .163 & $\mathbf{- . 8 3 3}$ & -.075 \\
HERS14 & .063 & $\mathbf{- . 7 3 6}$ & .025 \\
HERS47 & .251 & $\mathbf{- . 6 5 1}$ & -.051 \\
HERS42 & .038 & -.023 & $\mathbf{- . 7 2 9}$ \\
HERS43 & -.168 & -.131 & $\mathbf{- . 7 1 8}$ \\
HERS5 & -.137 & .082 & $\mathbf{- . 7 1 1}$ \\
HERS15 & -.085 & -.072 & $\mathbf{- . 6 8 1}$ \\
HERS9R & -.056 & -.022 & $\mathbf{- . 6 6 0}$ \\
\hline
\end{tabular}

Table 8:

Average Item Means and Standard Deviations for each Subscales of the HERS

$\underline{\text { Subscales }} \quad \underline{M} \quad \underline{\text { Std. Deviation }} \quad \underline{\mathrm{N}}$

\begin{tabular}{cccc}
\hline Interdependency & 4.27 & .58 & 322 \\
Attachment & 2.64 & .76 & 332 \\
Negative & 2.31 & .81 & 326 \\
Dependence & & & \\
HERS full scale & 3.07 & .40 & 311 \\
\hline
\end{tabular}


Table 9:

HERS Item Means and Standard Deviations

\begin{tabular}{ccc}
$\underline{\text { Item \# }}$ & $\underline{M}$ & $\underline{S D}$ \\
\hline HERS3 & 4.42 & .764 \\
HERS4 & 4.52 & .725 \\
HERS5 & 2.53 & 1.084 \\
HERS7 & 4.63 & .580 \\
HERS9R & 2.78 & 1.168 \\
HERS10 & 4.06 & .783 \\
HERS13 & 4.02 & 1.108 \\
HERS14 & 2.51 & .931 \\
HERS15 & 2.32 & 1.053 \\
HERS21 & 2.14 & 1.138 \\
HERS26 & 3.97 & 1.000 \\
HERS27 & 3.99 & .756 \\
HERS31 & 2.32 & 1.114 \\
HERS37 & 4.32 & .821 \\
HERS42 & 2.31 & .942 \\
HERS43 & 3.26 & 1.106 \\
HERS47 & 2.27 & .897 \\
HERS48 & 4.49 & .744 \\
\hline
\end{tabular}

Table 10:

Inter-correlations among Subscales for Full Sample and by Group Full Scale Group 1 Group 2

Subscale $\underline{\text { Att }} \quad \underline{\text { ND }} \quad \underline{\text { Att }}$ ND Att $\quad \underline{N D}$

\begin{tabular}{ccccccc}
\hline Interdependency & $.268^{* *}$ & $-.416^{* *}$ & $.288^{* *}$ & $-.395^{* *}$ & $.251^{* *}$ & $-.437^{* *}$ \\
Attachment & 1 & $-.119^{*}$ & 1 & & 1 & \\
Negative & & 1 & & 1 & & 1 \\
Dependence & & & & & & \\
\hline$* \mathrm{p}<.05$ level & & & & & & \\
$* * \mathrm{p}<.01$ level & & & & & &
\end{tabular}


Table 11:

HERS Subscales Cronbach Alpha for Full Sample and by Group

Subscale $\quad$ Full Sample $\quad$ Group 1

\begin{tabular}{llll}
\hline Interdependency & .878 & .885 & .871 \\
Attachment & .753 & .744 & .762 \\
Negative Dependence & .806 & .810 & .802 \\
HERS full scale & .745 & .755 & .735 \\
\hline
\end{tabular}

Table 12:

Intercorrelations Between Measures

\begin{tabular}{ccccc} 
& $\underline{\mathrm{INT}}$ & $\underline{\mathrm{ATT}}$ & $\underline{\mathrm{ND}}$ & $\underline{\mathrm{HERS}}$ \\
\hline HERS & $.766^{* *}$ & $-.286^{* *}$ & $-.680^{* *}$ & 1 \\
SODS & $.224^{* *}$ & & $-.153^{*}$ & $.294^{* *}$ \\
WAS & $.204^{* *}$ & $-.117^{*}$ & & $.242^{* *}$ \\
PAR now & $-.508^{* *}$ & $-.202^{* *}$ & $.367^{* *}$ & $-.427^{* *}$ \\
RPT hd & $.313^{* *}$ & $-.148^{*}$ & $-.218^{* *}$ & $.405^{* *}$ \\
RPTdd & $-.174^{* *}$ & & $.370^{* *}$ & \\
DSI er & & $-.269^{* *}$ & $-.148^{* *}$ & $.227^{* *}$ \\
DSI ip & $.159^{* *}$ & $-.212^{* *}$ & $-.215^{* *}$ & $.338^{* *}$ \\
DSI ec & $-.204^{* *}$ & $-.339^{* *}$ & & \\
DSI fo & $-.204^{* *}$ & $-.339^{* *}$ & & \\
MDS & & $.574^{* *}$ & & $-.421^{* *}$ \\
\hline
\end{tabular}

$* \mathrm{p}<.05$

$* * \mathrm{p}<.01$

INT - Interdependency subscale of HERS

ATT - Attachment subscale of HERS

ND - Negative Dependence subscale of HERS

HERS - Healthy Emotional Reliance Scale

SODS- Sexual Orientation Disclosure Scale

WAS- Worthington Autonomy Scale

PAIRnow- Personal Assessment of Intimacy in Relationships Inventory "how it is now" RPThd - Relationship Profile Test Healthy Dependency subscale

RPTdd - Relationship Profile Test Destructive Dependency subscale

DSIer - Differentiation of Self Inventory Emotional Reactivity subscale

DSIip - Differentiation of Self Inventory I-Position subscale

DSIec - Differentiation of Self Inventory Emotional Cutoff subscale

DSIfo - Differentiation of Self Inventory Fusion with Others subscale 
Table 13:

Intercorrelations between Relationship Satisfaction, Subscales and Outness

\section{RELSAT RPThd PAIRnow $\underline{\text { SODS }}$}

\begin{tabular}{lllll}
\hline INT &. $\mathbf{7 9 3}$ & $.313^{* *}$ & $-.508^{* *}$ & $.224^{* *}$ \\
ATT & $\mathbf{. 1 4 5 ^ { * * }}$ & $-.148^{*}$ & $-.202^{* *}$ & \\
ND & $-.549^{* *}$ & $-.218^{* *}$ & $.367^{* *}$ & $-.153^{* *}$ \\
HERS &. $\mathbf{7 3 3 * *}$ & $.405^{* *}$ & $-.427^{* *}$ & $.294^{* *}$ \\
RELSAT & $\mathbf{1}$ & $\mathbf{. 3 1 7 ^ { * * }}$ & $-.449^{* *}$ &. $\mathbf{3 8 3} * *$ \\
RPThd & & 1 & $-.232^{* *}$ & $.200^{* *}$ \\
PAIRnow & & & 1 & $-.162^{*}$ \\
SODS & & & & 1 \\
\hline
\end{tabular}

${ }^{*} p<.05$

${ }^{*} p<.01$

INT - Interdependency subscale of HERS

ATT - Attachment subscale of HERS

ND - Negative Dependence subscale of HERS

HERS - Healthy Emotional Reliance Scale

RELSAT - Relationship Satisfaction items

RPThd - Relationship Profile Test Healthy Dependency subscale

PAIRnow- Personal Assessment of Intimacy in Relationships Inventory "how it is now"

SODS- Sexual Orientation Disclosure Scale 
Figure 1: Healthy Emotional Reliance (HER) Model

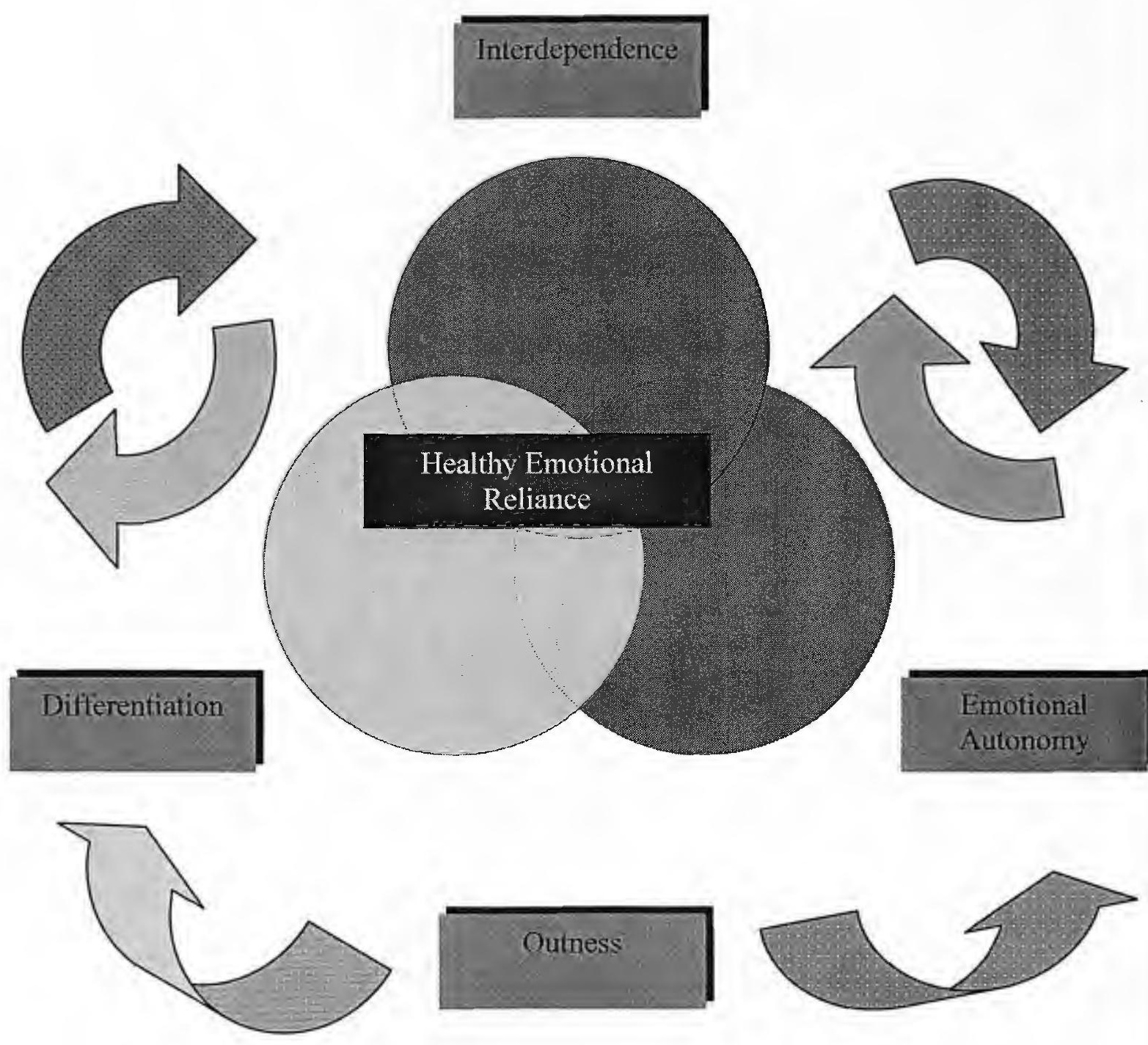


Figure 2: Three component scree plot Scree Plot

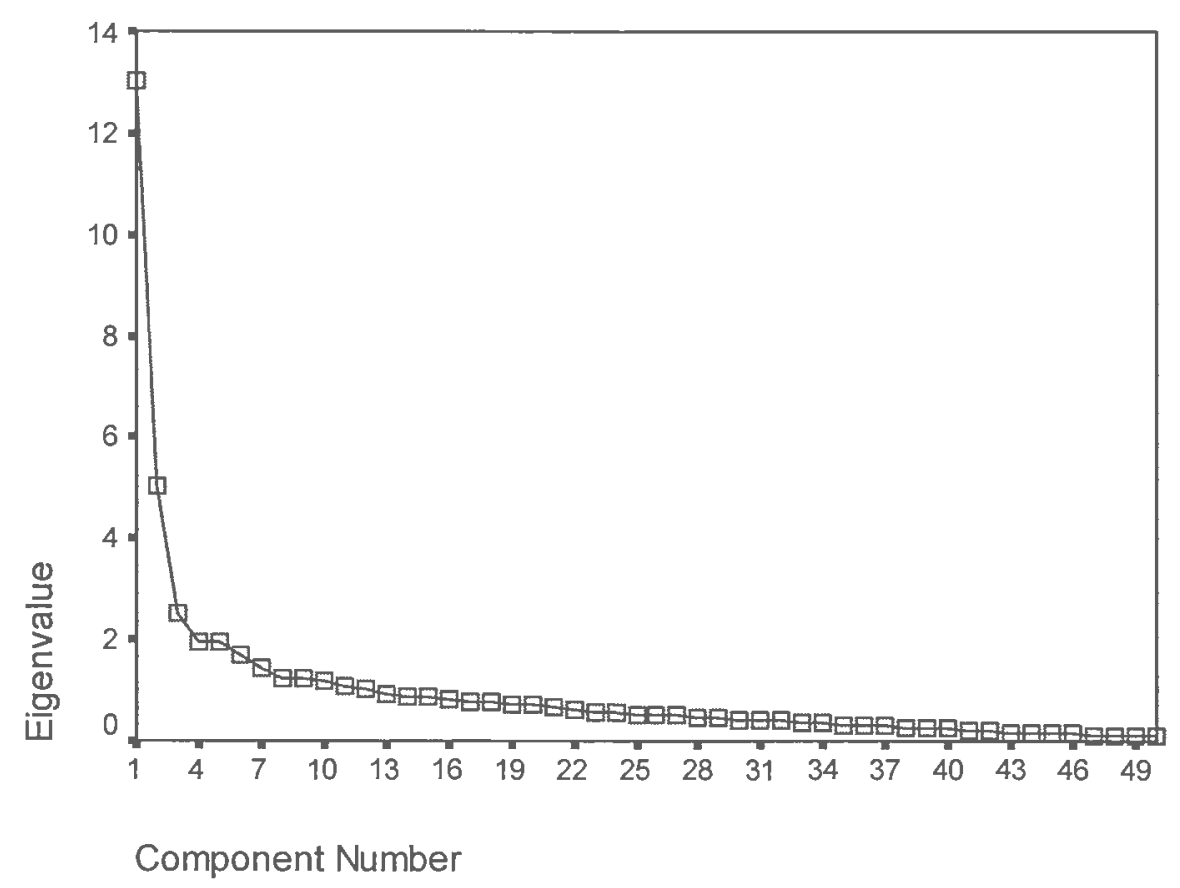




\section{Appendix A: \\ Healthy Emotional Reliance Scale (HERS)}

(Original Items)

For each of the questions below, please indicate how strongly you agree or disagree with the statements when considering yourself in your current relationship with another woman.

\section{You will be able to select one of the following by clicking on the answer of your choice:}

STRONGLY DISAGREE with the statement

DISAGREE with the statement

NEITHER AGREE OR DISAGREE with the statement

AGREE with the statement

STRONGLY AGREE with the statement

1. My partner and I still feel close, even if we can't spend all our time together.

2. I am sad when I cannot be with my partner.

3. My partner and I are comfortable sharing our deepest emotions with each other.

4. I feel safe and secure within my relationship with my partner.

5. I depend entirely on my partner for emotional stability.

6. My partner helps me feel emotionally stable.

7. My partner and I support each other.

8. I cannot imagine life without my partner.

9. I do not need my partner to be emotionally stable. $R$

10. I know that I can rely on my partner to meet many of my personal needs.

11. My partner and I are comfortable acknowledging our relationship to others.

12. Both our families accept our relationship.

13. I am satisfied with the level of closeness in my relationship.

14. I wish that my partner and I were more independent.

15. I seem to never want to be away from my partner.

16. I become confused about my own needs and wants when I am with my partner.

17. My partner and I are good for each other.

18. I feel that my relationship with my partner is psychologically healthy.

19. I feel that my relationship with my partner is emotionally satisfying.

20. My partner and I encourage each other to attain our own individual goals.

21. Sometimes I feel suffocated by my partner.

22. My partner and I are free to have other friendships.

23. There are times when I wonder if I need my partner too much.

24. I feel the most close to my partner when we are physically intimate.

25. I am most happy when I feel like my partner and I are emotionally connected.

26. I feel like my relationship is a give and take that is fairly equal.

27. I like that my partner and I are comfortable depending on one another.

28. Understanding myself as an independent person from my partner helps our relationship. 
29. Most times I know what my partner is feeling or wanting even before she tells me.

30. I think it is okay to rely on my partner for emotional connection and social needs.

31. Sometimes I feel resentful of the time my partner demands from me.

32. It is important that my partner and I have separate friends.

33. I am comfortable allowing my partner to be emotionally vulnerable with me.

34. It is important to me to feel connected to my partner.

35 . Sometimes I feel guilty for wanting too much of my partner's time.

36. My partner makes me feel safe.

37. I can be emotionally vulnerable with my partner.

38. My partner and I tell each other everything.

39. My out status affects my relationship.

40. Because I or my partner cannot be fully out, I/ she relies more heavily on her/me emotionally.

41. I would rather be with my partner than alone or with other friends.

42. Only my partner can comfort me when I am sad.

43. When my partner goes away for a long time, I feel like I am missing a part of myself.

44. If I were to have an emotional connection with another person, I would feel like I am cheating on my partner.

45. My relationship helps me grow personally.

46. I feel that my partner supports me in my ambitions.

47. I wish that my partner and I did not share everything.

48. I am secure in the love my partner has for me.

49. I feel that I am free to be angry with my partner.

50 . When I am with my partner it feels like the world melts away.

*Bolded $\mathbf{R}$ indicates reverse coded items 


\author{
Appendix B \\ Healthy Emotional Reliance Scale (HERS)
}

(Final Items)

For each of the questions below, please indicate how strongly you agree or disagree with the statements when considering yourself in your current relationship with another woman.

You will be able to select one of the following by clicking on the answer of your choice:

STRONGLY DISAGREE with the statement

DISAGREE with the statement

NEITHER AGREE OR DISAGREE with the statement

AGREE with the statement

STRONGLY AGREE with the statement

Factor 1: Interdependency

3. My partner and I are comfortable sharing our deepest emotions with each other.

4. I feel safe and secure within my relationship with my partner.

7. My partner and I support each other.

10. I know that I can rely on my partner to meet many of my personal needs.

13. I am satisfied with the level of closeness in my relationship.

26. I feel like my relationship is a give and take that is fairly equal.

27. I like that my partner and I are comfortable depending on one another.

37. I can be emotionally vulnerable with my partner.

48. I am secure in the love my partner has for me.

Factor 2: Attachment

5. I depend entirely on my partner for emotional stability.

9. I do not need my partner to be emotionally stable. $R$

15. I seem to never want to be away from my partner.

42. Only my partner can comfort me when I am sad.

43. When my partner goes away for a long time, I feel like I am missing a part of myself.

Factor 3: Negative Dependence

14. I wish that my partner and I were more independent.

21 . Sometimes I feel suffocated by my partner.

31. Sometimes I feel resentful of the time my partner demands from me.

47. I wish that my partner and I did not share everything.

*Bolded $\mathbf{R}$ indicates reverse coded items 
Appendix C: Measures

(In order of online appearance)

Demographics Questionnaire

Sexual Orientation Disclosure Scale (SODS; Miranda and Storm, 1989)

Worthington Autonomy Scale (WAS; Anderson et al., 1994)

(Emotional Autonomy sub-scale)

Differentiation of Self Inventory (DSI; Skowron \& Friedlander, 1998)

Relationship Profile Test (RPT; Bornstein \& Languirand, 2003)

The Personal Assessment of Intimacy in Relationships (PAIR) Inventory

(Schaefer \& Olson, 1981)

(Emotional Intimacy sub-scale)

Merger/ Disengagement Scale (MDS; Colwell, 1988)

(Merging sub-scale) 


\section{Demographic Questionnaire}

Thank you for taking the time to fill out this survey. Everything you write on this form will be kept confidential and anonymous. You must be 18 years or older, English speaking, and a woman currently in a monogamous, romantic relationship with another woman for at least the 12 months.

Please answer the following honestly, your time and effort is appreciated. If you have questions, please refer them to the researcher. Thanks you.

\section{Identification:}

Your age:

In what region of the country do you live?

What do you consider to be your ethnicity?

What do you consider to be your gender?

How do you privately identify in terms of sexual orientation?

How do you publicly identify in terms of sexual orientation?

\section{Education:}

What is the highest degree of education that you have obtained?

What is your current occupation?

What is your approximate annual household income?

\section{Relationship Status:}

How many year(s) and months have you and your partner/ girlfriend/ wife/ mate been a couple?

Do you live with each other?

If so, for how long have you lived together (in months)?

Do children currently live with you?

If so, how many?

What age(s)?

How long have they lived with you (in months)?

Is your partner also participating in this study? 
Below are listed 15 different types of relationships in which a woman may or may not be "out" to others about being romantically involved with another woman. Select the number that reflects the degree to which you are "out" to each relationship area.

The scale ranges from 1 (not out- nobody belonging to this relationships knows you are involved with another woman) to 7 (completely out- everybody in this type of relationship knows you are currently with a woman). If one of the relationships areas is not applicable, select "NA" and go on to the next item. Thank you.

\begin{tabular}{ccccccc} 
& \multicolumn{3}{c}{ (Online drop-down scale for each item) } \\
Not Out & \multicolumn{2}{c}{$\begin{array}{c}\text { Partially Out } \\
\text { Nampletely Out }\end{array}$} \\
NA & 2 & 3 & 4 & 5 & 6 & 7
\end{tabular}

1. To gay people

2. To your boss

3. To your co-workers

4. To your fellow students

5. To you doctor, lawyer, therapist, or other professional

6. To your mother

7. To your father

8. To your sibling(s)

9. To members of your extended family

10. To friends you have met since you acknowledged that you are attracted to at least one woman

11. To friends you had before you acknowledged you attraction to at least one woman

12. To casual acquaintances

13. To you pastor, priest, rabbi, etc.

14. To you fellow religious friends

15. To people involved with your housing

Please estimate the length of time in years to date that you have been quite sure you are attracted to women and have told a few people \# years. 
In reading the following statement, apply them to yourself and select the rating that best fits you.

(online drop-down menu for each item)

STRONGLY DISAGREE with the statement

DISAGREE with the statement

AGREE with the statement

STRONGLY AGREE with the statement

Please select one

1. I can be close to someone and give them space at the same time.

1234

2. I have learned to disagree with others and still like them.

1234

3. I trust most people.

1234

4. I believe that marriage should be for life.

1234

5. I find it difficult to thank others for what they do for me. R

6. I avoid being with others by working too much or staying busy. $R \quad 1234$

7. The more I trust others, the more trustworthy they become.

1234

8. My friends and family can count on me in a crisis.

1234

9. I try to be honest with people even if it may be painful to me or them. 1234

*Bolded $\mathbf{R}$ indicates reverse coded items 
These are questions concerning your thoughts and feelings about yourself and relationships with others. Please read each statement carefully and decide how much the statement is generally true of you on a 1 (not at all) to 6 (very) scale.

If you believe that an item does not pertain to you (e.g. one or both of your parents are deceased), please answer the item according to your best guess about what your thoughts and feelings would be in that situation.

Be sure to answer every item and try to be as honest and accurate as possible in your responses. Thank you.

Not at all true of me

(online drop down menu for each item)

$\begin{array}{llllll}1 & 2 & 3 & 4 & 5 & 6\end{array}$

1. People have remarked that I'm overly emotional. $R$

2. I have difficulty expressing my feelings to people I care for. $R$

3. I often feel inhibited around my family. $R$

4. I tend to remain pretty calm even under stress.

5. I'm likely to smooth over or settle conflicts between two people whom I care about. $\mathbf{R}$

6. When someone close to me disappoints me I withdraw from him or her for a time.

7. No matter what happens in my life, I know that I'll never lose my sense of who I am.

8. I tend to distance myself when people get too close to me. $R$

9. It has been said (or could be said) of me that I am still very attached to my parent(s). $R$

10. I wish that I weren't so emotional. $R$

11. I usually do not change my behavior simply to please another person.

12. My partner could not tolerate it if I were to express to her my true feelings about some things. $R$

13. Whenever there is a problem in my relationship, I'm anxious to get it settled right away. $R$

14. At times my feelings get the best of me and $I$ have trouble thinking clearly. $R$

15. When I am having an argument with someone, I can separate my thoughts about the issue from my feelings about the person.

16. I'm often uncomfortable when people get too close to me. $R$

17. It's important for me to keep in touch with my parent(s) regularly. $R$

18. At times, $I$ feel as if I'm riding an emotional roller coaster. $R$

19. There's no point in getting upset about things I cannot change.

20. I'm concerned about losing $m y$ independence in intimate relationships. $R$

21. I'm overly sensitive to criticism. $R$

22. When my partner is away for too long, I like I am missing a part of me. $R$ 
23. I'm fairly self-accepting.

24. I often fell that my partner wants too much from me. $R$

25. I try to live up to my parent's expectations. $R$

26. If I have had an argument with my partner, I tend to think about it all day. $R$

27. I am able to say no to others even when I feel pressure by them.

28. When one of my relationships becomes very intense, I feel the urge to run away from it. $R$

29. Arguments with my parent(s) or sibling(s) can still make me feel awful. $R$

30. If someone is upset with me, I can't seek to let it go easily. $R$

31. I'm less concerned that others approve of me than I am about doing what I think is right.

32. I would never consider turning to any of my family members for emotional support. $\mathbf{R}$

33. I find myself thinking a lot about my relationship with my partner. $R$

34. I' $m$ very sensitive to being hurt by others. $R$

35. My self-esteem really depends on how others think of me. $R$

36. When I'm with my partner, I often feel smothered. $R$

37. I worry about people close to me getting sick, hurt, or upset.

38. I often wonder about the kind of impression I create. $R$

39. When things go wrong, talking about them usually makes it worse. $R$

40. I feel thinks more intensely than others do.

41. I usually do what I believe is right regardless of what others say.

42. Our relationship might be better if my partner would give me the space I need.

43. I tend to feel pretty stable under stress.

Subscale Composition:

Emotional Reactivity: $1,6,10,14,18,21,26,30,34,38,40$

I Position: 4, 7, 11, 15, 19, 23, 27, 31, 35, 41, 43

Emotional Cutoff: 2, 3, 8, 12, 16, 20, 24, 28, 32, 36, 39, 42

Fusion With Others: 5, 9, 13, 17, 22, 25, 29, 33, 37

*Bolded $\mathbf{R}$ indicates reverse coded items 


\section{Relationship Profile Test (RPT; Bornstein \& Languirand, 2003)}

Please rate each of the statements below using the scale to the right. If a statement is very true of you, you'd select a high number, like 4 or 5 . If a statement is not at all true of you, you'd select a low number like 1 or 2 .

(online drop-down menu for each item)

Not at all true of me

Very much true of me

$\begin{array}{lllll}1 & 2 & 3 & 4 & 5\end{array}$

1. Other people seem more confident than I am.

2. I am easily hurt by criticism.

3. Being responsible for things makes me nervous.

4. I am most comfortable when someone else takes charge.

5. Others don't realize how much their words can hurt me.

6. It is important that people like me.

7. I would rather give in and keep the peace than hold my ground and win an argument.

8. I am happiest when someone else take the lead.

9. When I argue with someone, I worry that the relationship might be permanently damaged.

10. I sometimes agree with things I don't really believe so other people will like me.

11. Other people want too much from me.

12. When someone gets too close to me, I tend to withdraw.

13. I need to escape from it all every once in a while.

14. I wish I had more time by myself.

15. I prefer making decision on my own rather than listening to others' opinions.

16. I don't like to reveal too much personal information.

17. I'm sometimes wary of other people's motives.

18. I'm happiest when I'm working on my own.

19. Being independent and self-sufficient are very important to me.

20. When things aren't going right, I try to hide my feelings and be strong.

21. I believe that most people are basically good and well-meaning.

22. I am able to share my innermost thoughts and feelings with people I know well.

23. I am comfortable asking for help.

24. I don't worry about how other people see me.

25. Most of my relationships involve give-and-take, with both people contributing their share.

26. Most of my relationships are pretty much the way I want them to be- even if I could, I wouldn't change things.

27. I see myself as a capable person who copes well with disappointments and setbacks.

28. In my relationships I am comfortable offering support when the other person needs it and asking for support when I need it.

29. When I have a falling-out with someone, I am confident that the relationship will survive.

30. It is easy for me to trust people.

Subscales:

destructive overdependence: 1-10; dysfunctional detachment: 11-20; healthy dependency: 21-30 
The Personal Assessment of Intimacy in Relationships (PAIR) Inventory (Schaefer \& Olson, 1981)

(Emotional Intimacy sub-scale)

In reading the following statement, (1) apply them to your relationship as it is now and select the rating that best fits, and (2) select a second number to indicate how you would like your relationship to be.

(online pull-down menu for each item):

1 STRONGLY DISAGREE with the statement

2 DISAGREE with the statement

3 AGREE with the statement

4 STRONGLY AGREE with the statement

1. I can be close to someone and give them space at the same time

2. My partner listens to me when I need someone to talk to

3. I can state my feelings without her getting defensive

How it is now: How I'd like it to be:

\section{I often feel distant from my partner $R$}

1234

1234

5. My partner can really understand my hurts and joys

6. I feel neglected at times by my partner $R$

*Bolded $\mathbf{R}$ indicates reverse coded items 
Answer the following items while considering the relationship you are in currently that you consider to be of primary emotional involvement (referred to below as you "partner"). Use the following scale:
(a) strongly disagree
(b) disagree
(c) feel neutral
(d) agree
(e) strongly agree

1. Sometimes I think I need my partner too much.

2. I sometimes feel I am too "clingy" with my partner, that is, too dependent on her.

3. In my intimate relationship, I have found that when my partner must leave for any reason, I feel abandoned.

4. I tend to be reluctant to do anything or raise any subject that might jeopardize my relationship with my partner.

5. When my partner is upset, I find it difficult to focus on what I need, or on doing what I need to do.

6. I prefer that my partner rely on me for getting most of her intimacy needs met.

7. I tend to become depressed when my partner is inaccessible to me.

8. When I am not with my partner, I feel alone and alienated from the world.

9. When I am not with my partner, I have trouble figuring out how to spend my time.

10. I am most in love with my partner when I feel we are flowing together, two as one.

11. Sometimes my partner and I disagree because she wants to spend more close time with friends.

12. I enjoy the feeling of being "at one" with my partner, like we're to people flowing together into one being.

13. I am usually content to rely on my partner for meeting my social needs. 


\section{Appendix D: \\ Information for Participants}

\section{STUDY OF CLOSENESS IN FEMALE COUPLES}

Thank you for your participation in this investigation. Your willingness to participate is very important and greatly appreciated. This study explores the effects of closeness in relationships between women romantically involved with other women. The information gained through this research will be used to better understand how women relate in romantic relationships and how they define, view and experience closeness in their relationships. Your participation in this study is completely voluntary, confidential and anonymous.

Once you have read the below participant consent, understand and agree with it, please click on the url link to continue with the survey. This survey should take you approximately forty-five minutes. In order to participate, you must be at least 18 years old, English_speaking, and a woman in a monogamous, romantic relationship with another woman. This study is not concerned with the way you may identify in terms of your sexual orientation. Therefore, you may identify as lesbian, gay, straight, bisexual, or any other term you choose. It is only important that you are currently involved in a monogamous, romantic relationship with another woman and have been for at least the past year.

\section{Participant Consent}

I state that I am at least eighteen years old and wish to participate in the project described above conducted by A. Cassandra Golding of the University of Rhode Island, Department of Psychology. I understand that my research participation will take approximately forty-five minutes to anonymously complete an online survey.

\section{Confidentiality and Anonymity:}

My participation in this study is entirely voluntary and I am free to withdraw at any time. All information collected in this study is confidential and anonymous and my name will not be identified at any time. I understand that the data will be kept completely confidential and securely stored for three years following the completion of this study.

I also understand that there will be no way to link my individual responses with my identity. I am aware that I have the right to examine the overall results of the research and any conclusions drawn from these results.

\section{Risks or Discomfort and Benefits:}

I understand that the possible risks or discomforts of this study are minimal, although I may feel some discomfort answering questions about my private relationships. I further understand that the research is not designed to help me personally, but that the 
investigator hopes to learn more about closeness in female couples for all kinds of women.

Questions:

I am free to ask any questions I like. If I have more questions later, I may contact Cassandra Golding at 401-743-2907 and she will be happy to discuss them with me.

\section{Rights and Complaints:}

If I am not satisfied with the way this study is performed, I may phone Cassandra Golding at 401-743-2907, or Trish Morokoff, PhD. Department of Psychology, (401) 874-4239, anonymously, if I choose. I may also contact the office of the University of Rhode Island's Vice Provost for Graduate Studies, Research and Outreach, 70 Lower College Road, Suite 2, URI, Kingston, RI, (401) 874-4328.

I have read the consent form and my questions have been answered to my satisfaction. My participation in the online survey implies my consent to participate in this study.

Cassandra Golding

P.O. Box 28606

Providence, RI 02908

Thank you again for you help 


\section{Bibliography}

Anderson, R.A., Worthington, L., Anderson, W.T., Jennings, G. (1994) The development of an autonomy scale. Contemporary Family Therapy, 16(4), 329345 .

Barranti, C. C. R. (1998). Social work practice with lesbian couples. In G. P. Mallon (Ed.), Foundations of social work practice with lesbian and gay persons. (pp. 183-207). Binghamton, NY: The Harrington Park Press/The Haworth Press.

Berg-Cross, L. (1988). Lesbians, family process and individuation. Journal of college student psychotherapy, 3(1), 97-112.

Berzoff, J. (1989). Fusion and heterosexual women's friendships: Implications for expanding our adult developmental theories. Women \& Therapy, 8(4), 93-107.

Biaggio, M., Coan, S., \& Adams, W. (2002). Couples therapy for lesbians: Understanding merger and the impact of homophobia. Journal of Lesbian Studies, 6(1), 129-138.

Blumstein, P. \& Schwartz, P. (1983). American Couples: Money, work, sex. New York: William Morrow and Company.

Blumstein, P. W., \& Schwartz, P. (1990). Intimate relationships and the creation of sexuality. In D. M. McWhirter, S. A. Sanders, \& J. M. Reinisch (Eds.), Homosexuality/heterosexuality (pp. 307-320), New York: Oxford.

Blyth, S., \& Straker, G. (1996). Intimacy, fusion and frequency of sexual contact in lesbian couples. South African Journal of Psychology, 26(4), 253-256.

Bornstein, R. F. \& Languirand, M.A. (2003). Healthy dependency. New York: Newmarket.

Bornstein, R. F., Languirand, M. A., Geiselman, K.J., Creighton, J. A., West, M. A., Gallagher, M. A. \& Eisenhart, E. A. (2003). Construct validity of the Relationship Profile Test: A self-report measure of dependency-detachment. Journal of Personality Assessment, 80(1), 64-75.

Bowen, M. (1978). Family Therapy in Clinical Practice. New York: Aronson. Burch, B. (1982). Psychological merger in lesbian couples: A joint ego psychological and systems approach. Family Therapy, 9(3), 201-208.

Burch, B. (1985). Another perspective on merger in lesbian relationships. In L.Bosewater \& L. Walker (Eds.), Handbook of feminist therapy: Women's issues in psychotherapy (pp.100-109). New York: Springer. 
Burch, B. (1993). On intimate terms: The psychology of difference in lesbian relationships. Chicago: University of Chicago Press.

Burch, B. (1997). Other women: Lesbian/bisexual experience and psychoanalytic views of women. New York: Columbia University Press.

Carroll, L., Hoenigmann-Stovall, N., Turner, J. A., Gilroy, P. (1999). A comparative study if relational interconnectedness, merger, and ego development in lesbian, gay male, and heterosexual couples. Journal of Gay and Lesbian Social Services, 9(1), 51-67.

Causby, V., Lockhart, L, White, B., and Greene, K. (1995). Fusion and conflict resolution in lesbian relationships. Journal of Gay and Lesbian Social Services, $3(1), 67-82$.

Chodorow, N. (1978). The reproduction of mothering: Psychoanalysis and the sociology of gender. Berkeley: Univ. of California Press.

Connolly, C. M. (2005). A qualitative exploration of resilience in long-term lesbian couples. The Family Journal: Counseling and Therapy for Couples and Families, 13(3), 266-280.

Cronbach, L. J.\& Meehl, P.E.(1955). Construct validity in psychological tests. Psychological Bulletin, 52, 281-302.

Elise, D. (1986). Lesbian couples: The implications of sex differences in separationindividuation. Psychotherapy, 23(2), 305-310.

DeVellis, R.F. (2003). Scale Development: Theory and Applications, Second Edition. Thousand Oaks: Sage Publications.

Garnets, L. D., \& Kimmel, D. (1993). Psychology perspectives on lesbian and gay male experiences. New York: Columbia University Press.

Gilligan, C. (1982). In a different voice. Cambridge, MA: Harvard University Press.

Green, G.D. (1990). Is separation really so great? Women and therapy, 9(1-2), 87-104.

Green, R.J. \& Werner, P. D. (1996). Intrusiveness and closeness-caregiving: Rethinking the concept of family "enmeshment." Family Process, 35, 115-136.

Green, R.-J., Bettinger, M., \& Zacks, E. (1996). Are lesbian couples fused and gay male couples disengaged: Questioning gender straightjackets. In J. Laird \& R.-J. Green (Eds.) Lesbians and gays in couples and families: $A$ handbook for therapists (pp. 185-231). San Francisco: Jossey-Bass. 
Hancock, K. A. (1995). Psychotherapy with lesbians and gay men. In A.R.D'Augelli and C. J. Patterson (Eds.). Lesbian, gay and bisexual identities across the lifespan: psychological perspectives (pp. 398-432). New York: Oxford University Press.

Hornstein, R. T. (1996). An exploration of women's attitudes toward closeness in intimate relationships. Unpublished doctoral dissertation, Temple University, Philadelphia.

Hook, M. K., Gerstein, L.H., Detterich, L., and Grindley, B. (2003). How close are we? Measuring intimacy and examining gender differences. Journal of Counseling and Development, $81,462-472$.

Kirkpatrick, M. (1991). Lesbian couples in therapy. Psychiatric Annals, 21(8), 491496.

Krestan, J. \& Bepko, C. S. (1980). The problem of fusion in the lesbian relationship. Family Process, 19, 277-281.

Kurdek, L. A. (1995). Lesbian and Gay Couples. In A.R.D'Augelli and C. J. Patterson (Eds.). Lesbian, gay and bisexual identities across the lifespan: psychological perspectives (pp. 398-432). New York: Oxford University Press.

Jack, D. C. (1991). Silencing the Self. Cambridge, MA: Harvard University Press.

Jordan, J. V. (1997). In J. V. Jordan (Ed). Women's growth in diversity: More writings from the Stone Center. (pp. 311-330). New York: Guilford Press.

Lichtenberg, P. (1991). Intimacy as a function of autonomy and merging. The Gestalt Journal, 14(1), 27-43.

Mahler, M., Pine, F. \& Bergman, A. (1975). The Psychological birth of the human infant. N.Y.: Basic Books, Inc.

McKenzie, S. (1992). Merger in lesbian relationships. Women \& Therapy. Special Issue: Finding voice: Writing by new authors, 12(1-2), 151-160.

Mencher, J. (1997). Intimacy in lesbian relationships: A critical re-examination of fusion. In J. V. Jordan (Ed). Women's growth in diversity: More writings from the Stone Center. (pp. 311-330). New York: Guilford Press.

Mencher, J. \& Slater, S (1991). The lesbian family life cycle: A contextual approach. American Journal of Orthopsychiatry, 61, 372-382.

Miller, J. B. (1976). Toward a new psychology of women. Boston: Beacon Press. 
Minuchin, S. (1974). Family and family therapy. Cambridge: Harvard University Press.

Miranda, J., \& Storms, M. (1989). Psychological adjustment of lesbian and gay men. Journal of Counseling and Development, 68, 41-45.

Mitchell, V. (1988). Using Kohut's self psychology in work with lesbian couples. Women \& Therapy. Special Issue: Lesbianism: Affirming nontraditional roles, $8(1-2), 157-166$.

Pallant, J. (2001). SPSS Survival Manual. Philadelphia: Open University Press.

Pardie, L., \& Herb, C. R. (1997). Merger and fusion in lesbian relationships: A problem of diagnosing what's wrong in terms of what's right. Women \& Therapy, 20(3), 51-61.

Patterson, C. J. (1995). Sexual orientation and human development: An overview. Developmental Psychology, 31, 3-11.

Pearlman, S. F. (1988). Distancing and connectedness: Impact on couple formation in lesbian relationships. Women \& Therapy. Special Issue: Lesbianism: Affirming nontraditional roles, 8(1-2), 77-88.

Peplau, L. A., Chochran, S. D., Rook, K. \& Padesky, C (1978). Loving women: Attachment and autonomy in lesbian relationships. Journal of Social Issues, 34, 7-27.

Peplau, L. A. \& Garnets, L. D. (2000). A new paradigm for understanding women's sexuality. Journal of Social Issues, 56(2), 329.

Roper, K (1997). Lesbian couple dynamics and individual's psychological adjustment. Unpublished doctoral dissertation, California School of Professional, Alameda.

Redding, C. A., Maddock, J. E. \& Rossi, J. S. (2006). The sequential approach to measurement of health behavior constructs: Issues in selecting and developing measures. Californian Hournal of Health Promotion, 4(1), 83-101.

Salisbury (2003). Predictors of relationship satisfaction, sexual satisfaction and sexual frequency in female couples. Unpublished doctoral dissertation, University of Massachusetts at Amherst.

Schaefer, M.T. \& Olson, D.H. (1981). Assessing intimacy: the PAIR inventory. Journal of Marital and Family Therapy, 7, 47-60.

Skowron, E. A. \& Friendlander, M. L. (1998). The Differentiation of Self Inventory: Development and initial validation. Journal of Counseling Psychology, 45(3), 235-246. 
Slater, S. (1995). The lesbian family life cycle. New York: The Free Press.

Smally, S. (1987). Dependency issues in lesbian relationships. Journal of Homosexuality, 14, 125-135.

Smith, D.M., \& Gates, G.J. (2001). lesbian and gay families in the United States: Samesex unmarried partner households. Washington, DC: Human Rights Campaign.

Sullivan, A. (1995). Policy Issues In Gay and Lesbian Adoption. Adoption and Fostering, 19(4), 21-25.

Surrey, J. L. (1985). Self-in-relation: A theory of women's development. Wellesley, MA: Stone Center Working Paper Series.

Vargo, S. (1987). The effects of women's socialization on lesbian couples. In The Boston Lesbian Psychologies Collective (Eds), Lesbian Psychologies. Chicago, IL: University of Illinois Press. 